\title{
The goblet cell-derived mediator RELM- $\beta$ drives spontaneous colitis in Muc2-deficient mice by promoting commensal microbial dysbiosis
}

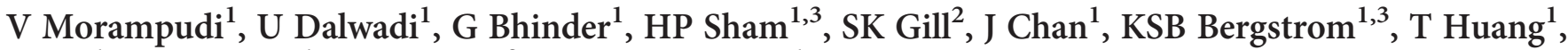 \\ $\mathrm{C} \mathrm{Ma}^{1}, \mathrm{~K}$ Jacobson $^{1}$, DL Gibson ${ }^{2}$ and BA Vallance ${ }^{1}$
}

Intestinal goblet cells are potentially key players in controlling susceptibility to ulcerative colitis (UC). Although impaired mucin (Muc2) production by goblet cells increases microbial stimulation of the colonic mucosa, goblet cells secrete other mediators that may influence or promote UC development. Correspondingly, Muc2-deficient $\left(^{-\prime-}\right)$ mice develop spontaneous colitis, concurrent with the dramatic upregulation of the goblet cell mediator, resistin-like molecule-beta (RELM- $\beta$ ). Testing RELM- $\beta$ 's role, we generated $M u c 2^{-\prime-} /$ Retnlb $^{-\prime-}$ mice, finding that RELM- $\beta$ deficiency significantly attenuated colitis development and symptoms compared with $M u c 2^{-\prime-}$ mice. RELM- $\beta$ expression in $M u c 2^{-{ }^{-}}$mice strongly induced the production/secretion of the antimicrobial lectin Reglll $\beta$, that exerted its microbicidal effect predominantly on Gram-positive Lactobacillus species. Compared with Muc2 ${ }^{-/} /$Retnlb $^{-/-}$mice, this worsened intestinal microbial dysbiosis with a selective loss of colonic Lactobacilli spp. in $\mathrm{Muc2}^{-{ }^{-}}$mice. Orally replenishing Muc2 $^{-1-}$ mice with murine Lactobacillus spp., but not with a probiotic formulation containing several human Lactobacillus spp. (VSL\#3), ameliorated their spontaneous colitis in concert with increased production of short-chain fatty acids. These studies demonstrate that the goblet cell mediator RELM- $\beta$ drives colitis in Muc2 ${ }^{-1-}$ mice by depleting protective commensal microbes. The ability of selective commensal microbial replacement to ameliorate colitis suggests that personalized bacterial therapy may prove beneficial for treatment of UC.

\section{INTRODUCTION}

Ulcerative colitis (UC) is a form of inflammatory bowel disease (IBD) characterized by severe mucosal inflammation and ulceration in the large intestine. This debilitating disease is thought to develop due to exaggerated bacterial stimulation of the mucosal immune system. ${ }^{1}$ This may reflect changes in the gut microbiota, as the microbial populations of UC patients are known to be dysbiotic, often showing less biodiversity, fewer beneficial microbes, and increased pathobiont numbers than the microbiota of healthy individuals. ${ }^{2,3}$ Moreover, UC patients often display structural or functional defects in their normally protective colonic mucosal barriers. This includes the intestinal mucus barrier, which is largely dependent on the release of goblet cell-derived mucin (Muc2), the major secretory mucin within the gastrointestinal tract. ${ }^{4}$ A highly glycosylated protein, upon its release, Muc2 is hydrated, forming the mucus layer that prevents microbes as well as luminal antigens from contacting the epithelial surface. ${ }^{5,6}$ Several studies on inflamed UC patient tissues have shown reduced goblet cell numbers, and a thinner than normal mucus layer. ${ }^{7}$ These changes are not necessarily secondary to disease, but may instead represent a primary defect since functional impairments in mucus are observed in some IBD patients even with inactive disease and in mouse models of IBD prior to overt inflammation. ${ }^{8-10}$ Correspondingly, mice that lack $M u c 2$, or suffer missense mutations in $M u c 2$ that impair its release and function develop spontaneous colitis that depends on the presence of gut microbes. ${ }^{11,12}$ Although clearly demonstrating that impaired

\footnotetext{
${ }^{1}$ Division of Gastroenterology, Department of Pediatrics, Child and Family Research Institute, Vancouver, British Columbia, Canada and ${ }^{2}$ Department of Biology, Okanagan, University of British Columbia, Kelowna, British Columbia, Canada. Correspondence: BA Vallance (bvallance@cw.bc.ca)

${ }^{3}$ Present addresses: Brigham and Women's Hospital, Department of Pulmonary and Critical Care Medicine, Boston, MA 02115, USA (H.P.S.); Oklahoma Medical Research Foundation, Oklahoma City, OK 73104-5097, USA (K.S.B.B.)
} 
function and loss of goblet cells predisposes to colitis, it remains uncertain whether additional or concurrent changes in goblet cell function also have a role. Goblet cells produce important mucosal defense factors like trefoil factor 3 (TFF3) and resistinlike molecule-beta (RELM- $\beta$ ). RELM- $\beta$ was initially thought to have a role in insulin resistance in rodents; however, it was subsequently found to impact immune regulation and host defense against intestinal nematode infections. ${ }^{13,14}$ RELM- $\beta$ is secreted apically into the intestinal lumen ${ }^{15}$ and regulates susceptibility to intestinal inflammation by promoting mucosal barrier integrity. ${ }^{16}$ RELM- $\beta$ expression is induced by commensal colonization in germ-free mice ${ }^{17}$ and its secretion is known to be upregulated in several animal models of gut inflammation. ${ }^{18-20}$ These include dextran sodium sulfate colitis where RELM- $\beta$ was found to leak into the colonic lamina propria, activating macrophages to secrete the cytokine tumor necrosis factor $-\alpha{ }^{21}$ Interestingly, although RELM- $\beta$ has been shown to regulate the expression of the antimicrobial lectins RegIII $\beta$ and RegIII $\gamma$, it is unclear whether it has any role in shaping the gut microbiota.

Based on preliminary studies showing that RELM- $\beta$ was strongly upregulated in the colons of colitic Muc2-deficient $\left({ }^{-1}\right)$ mice, we tested its role during the spontaneous colitis that develops in these mice. We hypothesized that in the absence of the mucus barrier, goblet cells would release RELM$\beta$ to protect the colonic mucosal surface by upregulating RegIII $\beta$ and RegIII $\gamma$ to create an antimicrobial zone overlying the epithelium. To test this, we generated mice lacking both Muc2 and RELM- $\beta$ and compared their colitis development with that in $M u c 2^{-/-}$mice. Although our hypothesis was partially confirmed, as RegIII $\beta$ expression was dramatically induced in $\mathrm{Muc}^{-1-}$ mice but largely lacking in $\mathrm{Muc2} 2^{-1-}$ / Retnlb $^{-/-}$mice, its antimicrobial activity led to a dysbiotic gut microbiome deficient in Lactobacillus spp. Over time, this led to a dramatically worsened clinical course in the $M u c 2^{-/-}$ mice that was reversible by targeted replacement by murine, but not human-derived Lactobacillus spp. These studies demonstrate that it is the goblet cells themselves that drive the colitis in $M u c 2^{-/-}$mice, by inducing a RELM- $\beta$-dependent intestinal microbial dysbiosis.

\section{RESULTS}

Muc2 $^{-/-}$mice rapidly develop spontaneous colitis

Assessment of $\mathrm{Muc}^{-/-}$mice raised in our facility confirmed previous reports of spontaneous colitis development under physiological conditions. While $M u c 2^{-/-}$mice appeared completely healthy just after weaning (1 month), as they aged, they developed progressive diarrhea along with sporadic rectal prolapse (RP) (Figure 1a and b). Once killed, their colons were found to be thickened and reddish in color, containing soft rather than formed stool. Histological analysis revealed that compared with age-matched C57BL/6 mice, 2-month-old $M u c 2^{-/-}$mouse colon tissues showed overt crypt hyperplasia, occasional crypt abscesses, as well as modest inflammatory cell infiltration and submucosal edema (Figure 1c). Staining with
Periodic acid-Schiff revealed markedly reduced acidic and neutral staining of mucins in the colons of $\mathrm{Muc}^{-/-}$mice (Figure 1d), however, some staining was still evident; indicating the presence of other mucins.

To assess whether the remaining Periodic acid-Schiff staining reflected compensatory increases in other mucins, transcript levels for Muc3, Muc5AC, Muc6, and Muc13 were assayed. The transcription of these mucin genes in $M u c 2^{-/-}$ mice was similar to levels in C57BL/6 mice, suggesting no overt compensatory response (Figure 1e). As goblet cells not only secrete mucins, but also RELM- $\beta$ and TFF3, we next analyzed their gene transcription. As shown in Figure 1f, a significant 290 -fold increase in Retnlb gene transcription was observed in $M u c 2^{-/-}$mice as compared with C57BL/6 mice. A dramatic increase in RELM- $\beta$-positive immunostaining was also observed in $\mathrm{Muc2}^{-/-}$mice, localizing solely to goblet cells (Figure 1g). In contrast, little if any RELM- $\beta$ staining was seen in age-matched C57BL/6 mice. The dramatic elevation in Retnlb was selective, as no significant changes in Tff3 transcript levels, or the TFF3 protein were identified in $M u c 2^{-/}$mice, as compared with C57BL/6 mice. Thus, in the absence of Muc2, the goblet cell mediator RELM- $\beta$ is strongly upregulated.

\section{Spontaneous colitis symptoms are reduced in Muc2 $^{-/-} /$Retnlb $^{-/-}$mice}

To determine whether RELM- $\beta$ had any role in the spontaneous colitis of $M u c 2^{-/-}$mice, we generated a mouse strain $\left(\mathrm{Muc}^{-/-} /\right.$Retnlb $\left.^{-/-}\right)$lacking both Muc2 and RELM- $\beta$. The F1 and F2 progeny obtained from crossbreeding Retnlb ${ }^{-/-}$ and $\mathrm{Muc2}^{-/-}$mice were genotyped (Supplementary Figure S1A online) using published primers. ${ }^{12,22}$ Colon tissues from the parental as well as $M u c 2^{-/-} /$Retnlb $^{-/-}$mouse strains were immunostained for Muc2 and RELM- $\beta$. As expected, Muc2 was readily detected in the goblet cells of C57BL/ 6 and Retnlb $^{-/-}$mice, but was undetectable in $M u c 2^{-/-}$or Muc $2^{-/-} /$Retnlb $^{-/-}$mice (Supplementary Figures S1B and S1C). Similarly, when colon tissues were stained for RELM- $\beta$, only $M u c 2^{-/-}$mice displayed positive staining, whereas it was not detected in healthy C57BL/6 mice, or in mouse strains lacking Retnlb (Supplementary Figures S1D and S1E).

Once generated, the $M u c 2^{-/-} /$Retnlb $^{-/-}$mice were monitored for breeding success, changes in body weight and clinical symptoms such as RP and stool consistency. Similar to C57BL/6 mice, Muc2 ${ }^{-/-} /$Retnlb $^{-/-}$mice were very fertile, producing 4-5 litters of normal size (8-10 pups) over their reproductive lives. In comparison, $\mathrm{Muc} 2^{-/-}$mice only produced 3-4 litters of smaller size (4-8 pups). Moreover, significant differences in body weights were noted between mouse strains as early as 2 months of age. Compared with C57BL/6 mice, $\mathrm{Muc2}{ }^{-/-}$mice were smaller and weighed significantly less $(11,4$, and $14 \%)$ at 2, 4, and 6 months of age,

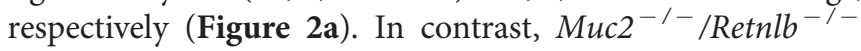
mice weighed significantly more $(8,6$, and $5 \%)$ than C57BL/6 mice at these time points (Figure $2 \mathbf{a}$ ). 


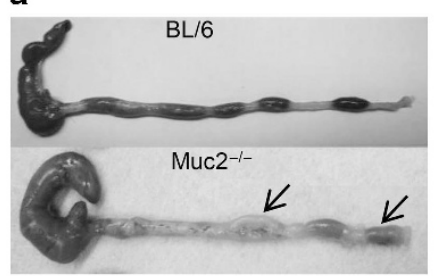

d

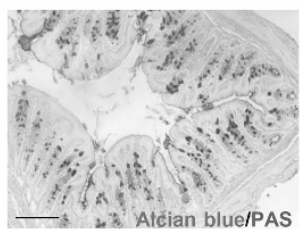

b

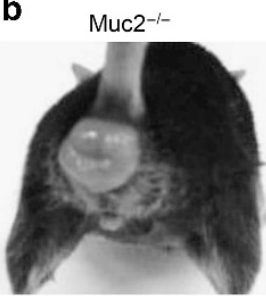

Muc2-/-

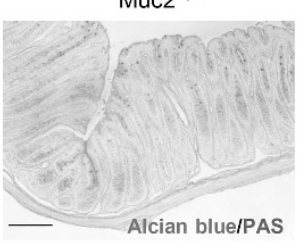

c

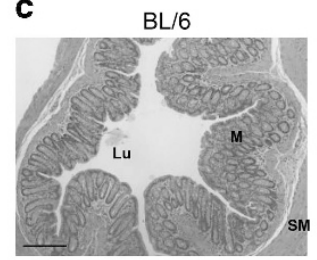

Muc2-/-

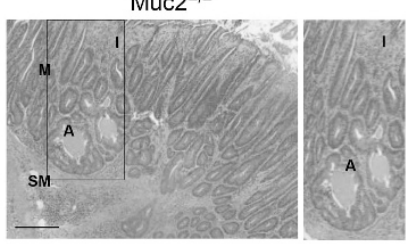

e

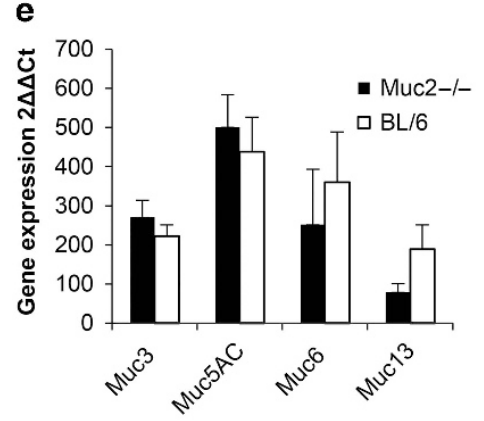

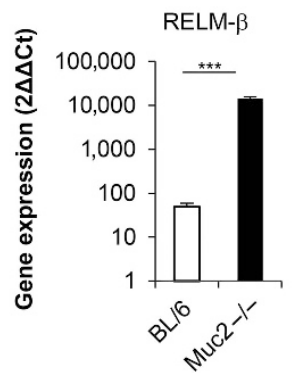
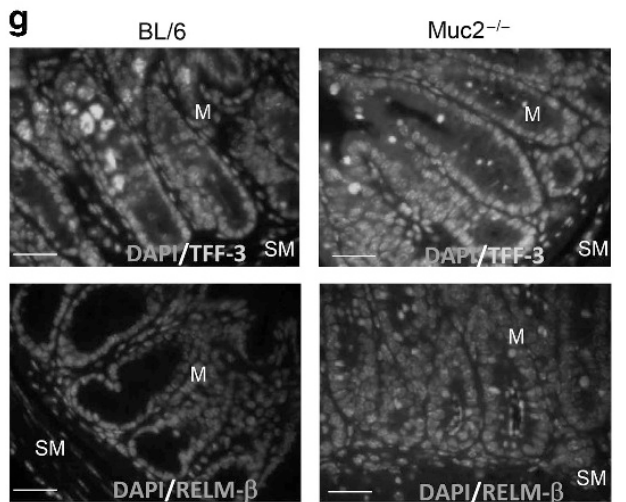

Figure 1 Clinical features of spontaneous colitis in $\mathrm{Muc2}^{-/-}$mice. (a) Macroscopic examination showed that the colons of $\mathrm{Muc2}^{-/-}$mice were swollen and contained soft and loose stool when compared to the colons of C57BL/6 mice. (b) Rectal prolapse typically manifests in Muc2 ${ }^{-/-}$mice aged between 1 months to 4 months. (c) H\&E staining of colon tissues obtained from Muc2 ${ }^{-1-}$ mice aged 2 months demonstrating significant inflammation characterized by inflammatory cell infiltration, crypt hyperplasia and abscesses and submucosal edema (original magnification $\times 200$ ). (d) Staining for acidic (Alcian blue) and neutral (PAS) carbohydrates showed significant loss of mucin production in Muc2 ${ }^{-/-}$mice. (e) Mucin gene transcription for Muc3, Muc5AC, Muc6, and Muc13 showed no significant differences between C57BL/6 and Muc2 ${ }^{-/-}$mice. (f) In contrast, when analyzed for the transcription of other goblet cell-derived factors such as Retnlb and Tff3, the transcription of Retnlb was significantly higher in Muc2 ${ }^{-1-}$ mice. (g) Immunostaining also revealed increased positive staining for RELM- $\beta$ in Muc2 ${ }^{-/}-$mice whereas the staining for TFF3 was similar to that in C57BL/6 mice (original magnification $\times 630$ ). $n \geqslant 5$ per each group, Student's $t$-test, ${ }^{* * *} P<0.0001, A$, crypt abscess; H\&E, hematoxylin and eosin; I, inflammatory cell infiltration; Lu, intestinal lumen; M, mucosa; Muc, mucin; O, edema; PAS, Periodic acid-Schiff; RELM- $\beta$, resistin-like molecule-beta; SM, sub-mucosa.

As $\mathrm{Muc2}^{-/-}$mice aged, they displayed overt symptoms of spontaneous colitis. Prior to reaching 2 months of age, $6 \%$ developed overt RP (requiring euthanization), while $17 \%$ of the original cohort developed RP between 2 and 4 months of age. Another 17\% developed RP between 4 and 6 months of age, reaching a total $40 \%$ of $M u c 2^{-/-}$mice developing RP by 6 months of age. In contrast, only $17 \%$ of $M u c 2^{-/-} /$Retnlb $^{-/-}$ mice developed RP over the same time course, with $3 \%$ developing it before 2 months, $5 \%$ between 2 and 4 months and $9 \%$ between 4 and 6 months of age (Figure $2 \mathbf{b}$ ). Furthermore, when the two mouse strains were analyzed for stool consistency over their first 6 months, $59 \%$ of $M u c 2^{-/-}$mice developed loose stools, vs. only $30 \%$ of $M u c 2^{-1-} /$ Retnlb $^{-1-}$ mice (Figure 2c). Overall, $M u c 2^{-/-} /$Retnlb $^{-/-}$mice suffered significantly fewer colitic symptoms (RP and loose stools) as compared with $M u c 2^{-/-}$mice $\left(P<0.05, \chi^{2}\right.$-test), indicating 

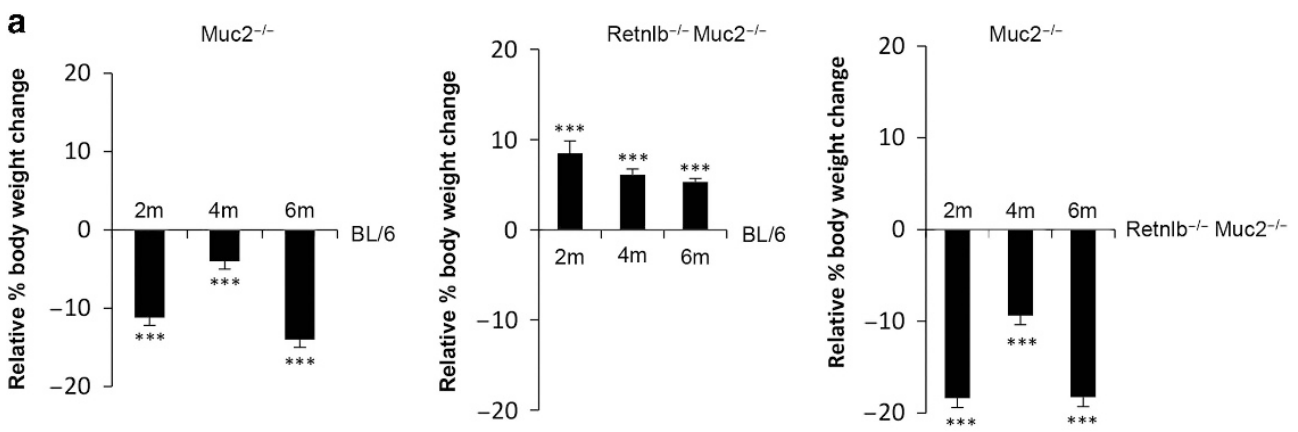

b

Development of rectal prolapse (RP)
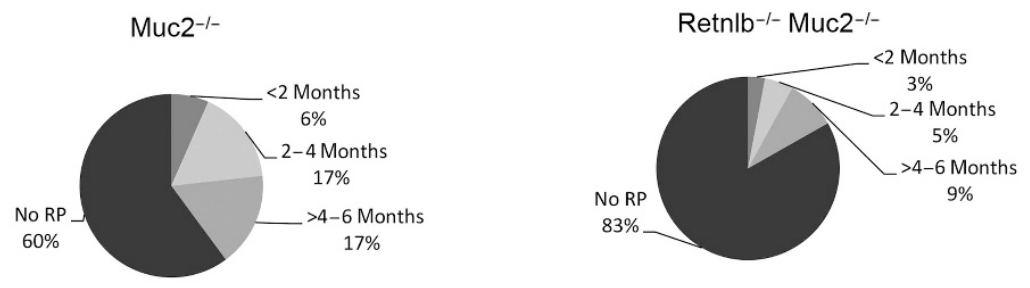

C Presence of loose stools (Diarrhoea)
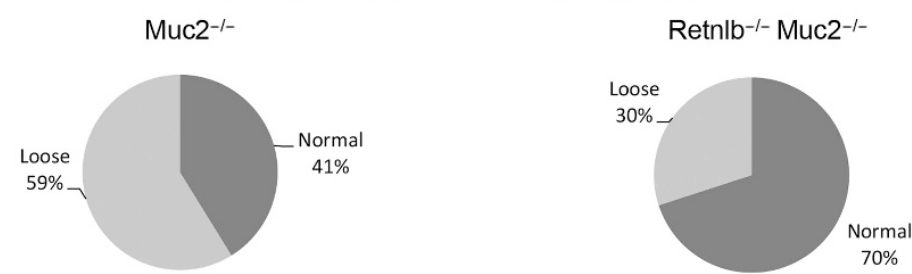

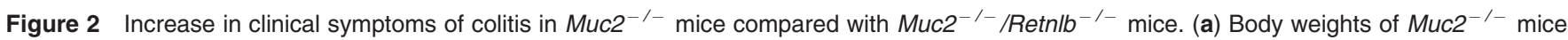
recorded at 2, 4, and 6 months of age and the results shown as the percent (\%) change in body weight after normalization to body weights of C57BL/6 mice (left and middle panel) and $\mathrm{MuC2}^{-/-} /$Retnll $^{-/-}$mice (right panel) at respective time points. (b) Manifestation of rectal prolapse according to its age of appearance $\left(<2,2-4\right.$, or $>4$ months) is higher in $\mathrm{Muc2}^{-1-}$ mice when compared with $\mathrm{Muc2}^{-1-} / \mathrm{Retnl}^{-1-}$ mice. (c) The percentage of mice with loose stools is also higher Muc2 ${ }^{-/-}$mice when compared with $\mathrm{Muc2}^{-/-} /$Retnll ${ }^{-/-}$mice. $n \geqslant 15$ mice were used for each clinical symptom measured. Twoway ANOVA analysis followed by Bonferroni's post-test was used to calculate time-dependent significance between each group of mice, ${ }^{\star \star \star} P<0.0001$. ANOVA, analysis of variance; Muc, mucin; RELM- $\beta$, resistin-like molecule-beta.

a pro-colitic role for RELM- $\beta$ expression in $\mathrm{Muc2}^{-/-}$mice under physiological conditions.

\section{RELM- $\beta$ expression worsens colonic crypt pathology in 4 months old $\mathrm{Muc2}^{-1-}$ mice}

Since almost half the $\mathrm{Muc2}^{-/-}$mice required killing before 6 months of age, we decided to focus future studies on mice at 2 and 4 months of age. Microscopic analysis of hematoxylin and eosin stained colon sections at 2 months revealed modest submucosal edema, crypt hyperplasia as well as mucosal inflammation in both mouse strains. Immune/inflammatory cell infiltration was widespread in the $M u c 2^{-1-}$ mice but less overt in the $M u c 2^{-/-} /$Retnlb $^{-/-}$mice, whereas crypt hyperplasia was greater in the $\mathrm{Muc2^{-/- }} / \mathrm{Retnlb}^{-/-}$mice, with total pathology scores roughly similar between the two groups ( $3.8 \pm 0.6$ vs. $4.8 \pm 0.8$; Figure 3a). Between 2 and 4 months of age, colonic pathology in the $\mathrm{Muc2}^{-/-} /$Retnlb $^{-/-}$ mice increased only modestly to $7.2 \pm 0.5$, largely due to the increased immune/inflammatory cell infiltration. In contrast, colonic tissue damage was dramatically greater in 4-month-old
$M u c 2^{-1-}$ mice. Although edema, crypt hyperplasia, and inflammatory cell infiltration were all increased, their most significant pathological features reflected increased crypt epithelial damage as well as crypt abscesses. As compared with $M u c 2^{-/-} /$Retnlb $^{-/-}$mice, $M u c 2^{-/-}$crypts were highly irregular and distorted in shape, while intercryptal spaces were greatly dilated. Crypt abscesses containing neutrophils and necrotic epithelial cells were rare in $\mathrm{Muc2}^{-/-} /$Retnlb $^{-/-}$ mice, but very frequent in $M u c 2^{-/-}$mice (Figure $3 \mathbf{b}$ ), along with large numbers of neutrophils found within the crypt epithelium. When quantified, colonic pathology increased a dramatic $250 \%(12.2 \pm 1.6)$ in $M u c 2^{-/-}$mice by 4 months of age, reaching a level significantly $(P<0.001)$ greater than that of $M u c 2^{-1-} /$ Retnlb $^{-1-}$ mice (Figure 3c).

\section{Muc2 $^{-/-}$and Retnlb ${ }^{-/-} /$Muc2 $^{-/-}$mice display only} modest differences in colonic inflammation

The differential progression of the colitis observed in $\mathrm{Muc2}^{-/-}$ and $\mathrm{Muc2}^{-/-} / \mathrm{Retnlb}^{-/-}$mice led us to investigate whether it reflected differences in inflammatory and immune cell 
a

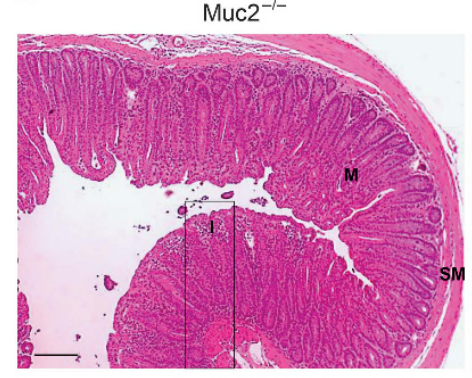

b

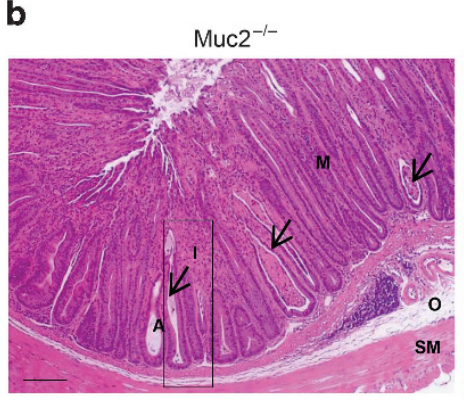

2 Months
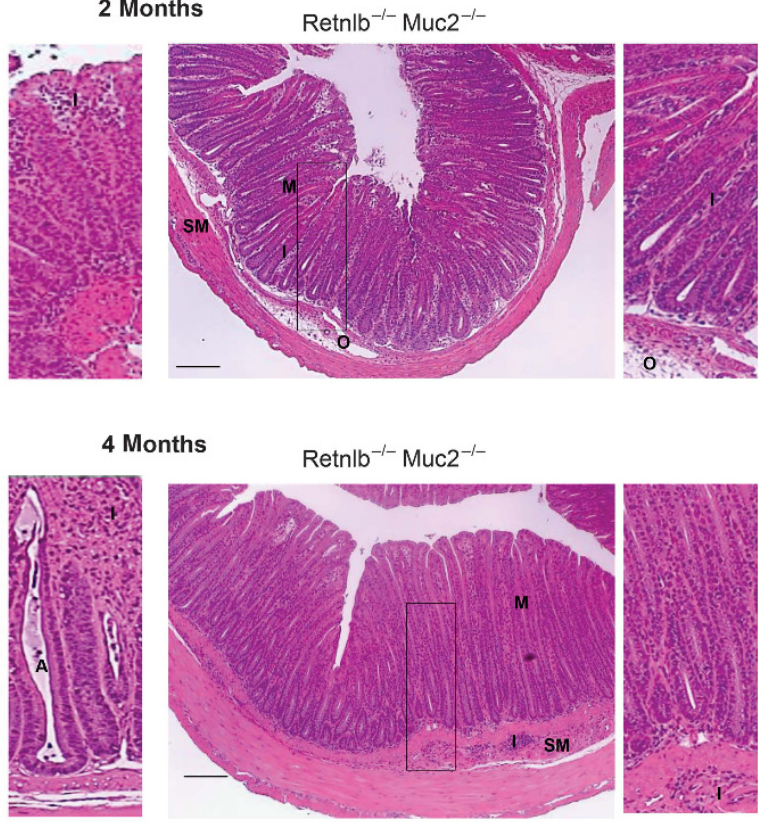

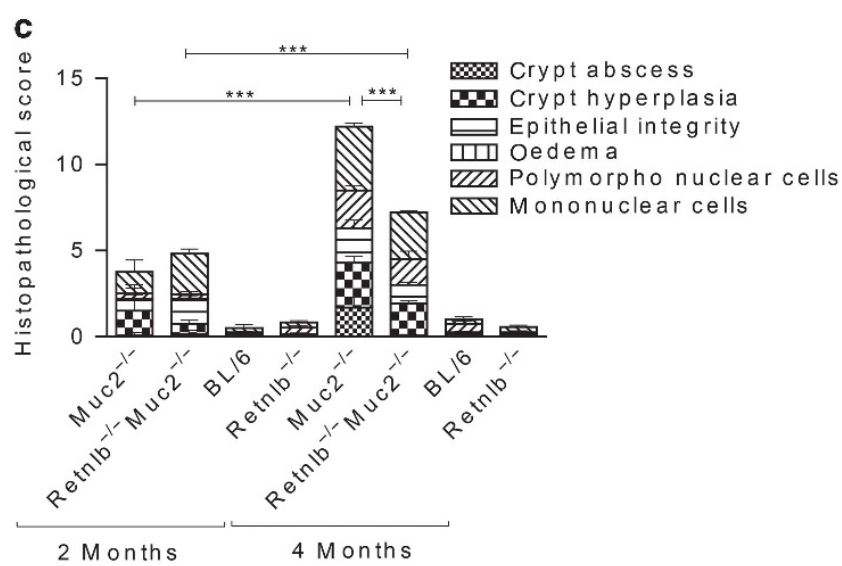

Figure 3 Colonic crypt pathology worsens over time in Muc2 ${ }^{-/-}$mice. H\&E stained colonic cross sections from (a) 2- and (b) 4-month-old Muc2 $2^{-/-}$ and $\mathrm{MuC2}^{-/-} /$Retnlb $^{-/-}$mice. Both mouse strains show a significant increase in colonic histopathology between 2 and 4 months of age, however, the

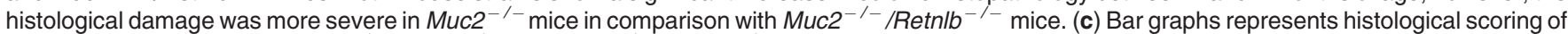

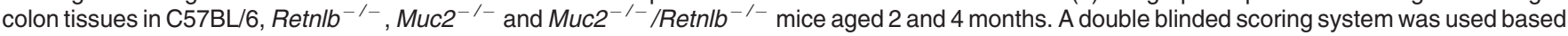
on following criteria: (i) hyperplasia (0, no change; 1, 1-50\%; 2, 51-100\%; 3, >100\%), scored as percentages above the height of C57BL/6 mice; (ii) crypt abscess (0, no abscess; 1 , few crypts exhibit abscess; 2, about half of the crypts exhibit abscess; 3 , over $70 \%$ of the crypts exhibit abscesses); (iii) epithelial integrity ( 0 , no pathological changes detectable; 1 , few cells slough; 2 , epithelial surface rippled; 3 , severely disrupted/damaged, large amount of epithelial cell sloughing); (iv) edema (0, no change; 1 , mild change; 2 , moderate change, and 3 , profound change) and ( $\mathrm{v}$ ) mononuclear and polymorphonuclear cells $(0$, no change; $1,<20 ; 2,21-50 ; 3,51-70 ; 4,>70) . n \geqslant 15$ Mice, original magnification $\times 200$. Two-way ANOVA, ${ }^{* \star \star} P<0.0001$, (Mean \pm s.e.m.). ANOVA, analysis of variance; I, inflammatory cell infiltration; M, mucosa; Muc, mucin; O, edema; RELM- $\beta$, resistin-like molecule-beta; SM, sub-mucosa.

recruitment to the colon. Immunostaining for T lymphocytes $(\mathrm{CD} 3+)$, macrophages $(\mathrm{F} 4 / 80+)$, and neutrophils $($ Ly6g +$)$ revealed that all three cell types were in greater abundance in the colons of $\mathrm{Muc2}^{-1-}$ and $\mathrm{Muc2} 2^{-1-} /$ Retnlb $^{-1-}$ mice, as compared with C57BL/6 tissues (Figure 4a-c). At 2 months of age, T lymphocyte numbers were modestly, but significantly higher in $\mathrm{Muc2}^{-/-}$mice as compared with $\mathrm{Muc2}^{-/-}$, Retnlb $^{-1-}$ mice, whereas neutrophil and macrophage numbers were similar. Interestingly, by 4 months of age, macrophage numbers remained constant, whereas $\mathrm{T}$ lymphocyte and neutrophil numbers increased in the tissues of $\mathrm{Muc2}^{-/-}$/
Retnlb $^{-/-}$mice to levels similar to $M u c 2^{-/-}$mice, despite their comparatively reduced tissue pathology.

We next examined whether any overt differences in inflammatory cytokine gene transcription (tumor necrosis factor- $\alpha$, interferon- $\gamma$, interleukin (IL)-6, IL-17F, IL-23) could explain the worsened outcomes in the $\mathrm{Muc2}^{-1-}$ mice. Surprisingly, we noted only minimal differences in transcript levels of these genes between $\mathrm{Muc2}^{-1-}$ mice and $\mathrm{Muc2}^{-1-}$ / Retnlb $^{-1-}$ mice at both 2 and 4 months (Figure 4d and e). The only notable differences were significantly greater $I L-22$ gene transcription in 2-month-old Muc2 ${ }^{-/-} /$Retnlb $^{-/-}$mice 

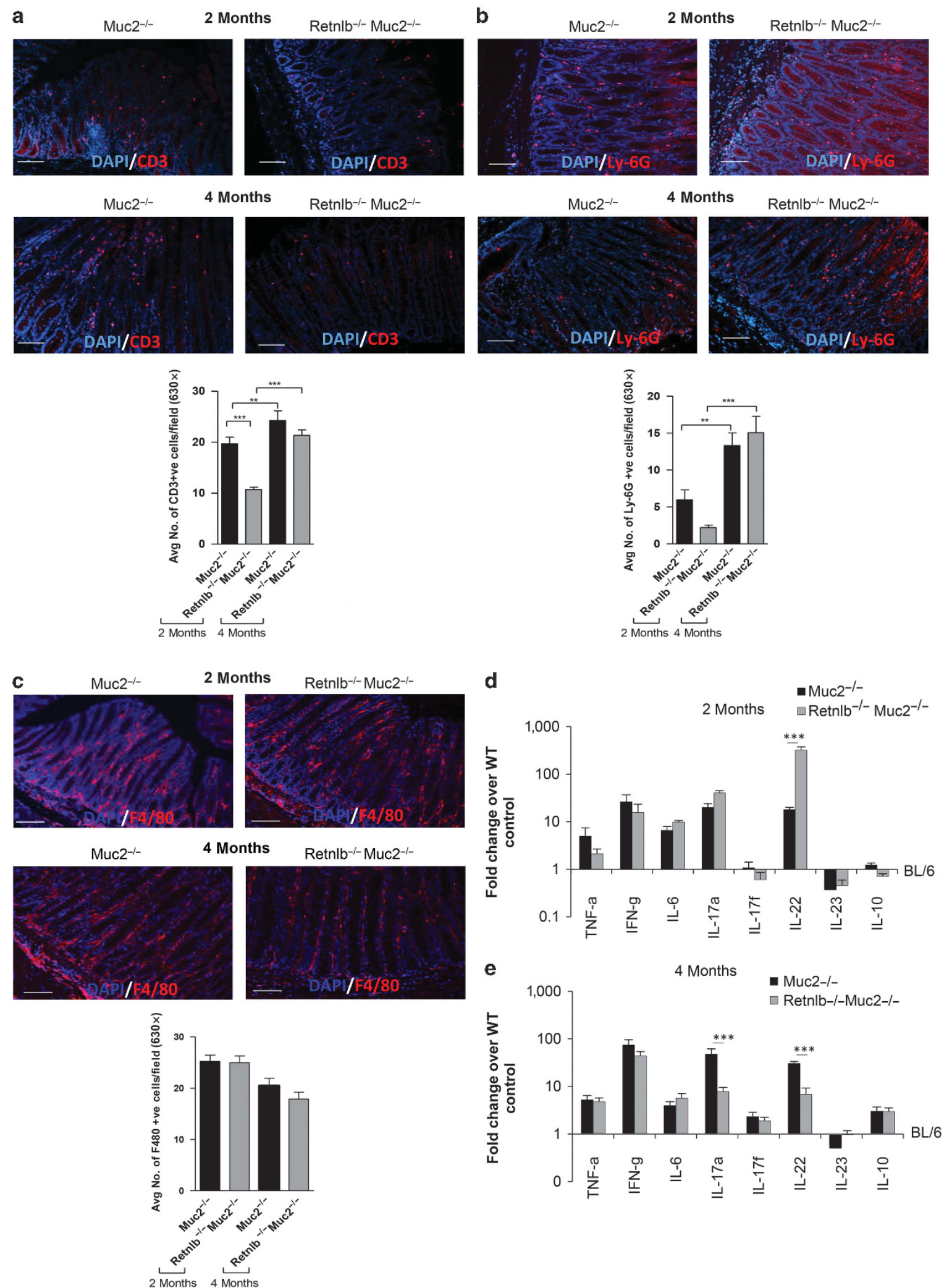

Figure 4 Inflammatory cell responses are similar in $M u c 2^{-/-}$and $M u c 2^{-/-} /$Retn/b ${ }^{-1-}$ mice. Colon tissue sections collected from 2-and 4-month-old mice were immunostained for (a) T lymphocytes (CD3), (b) neutrophils ( $\mathrm{Ly}-6 \mathrm{~g})$ and (c) macrophages (F4/80). Bar graphs represent the average number of positive cells identified per field $(\times 630)$. Tissues were also analyzed for gene transcription of pro- and anti- inflammatory cytokines in Muc2 ${ }^{-/-}$and Muc2 $^{-1-} /$ Retnlb $^{-1-}$ mice aged (d) 2 and (e) 4 months of age. $n=12$ Mice were analyzed per each group, original magnification $\times 630$. MANOVA ${ }^{* *} P<0.001,{ }^{* \star *} P<0.0001$. MANOVA, multivariate analysis of variance; Muc, mucin. 
vs. $M u c 2^{-/-}$mice, whereas both $I L-17 A$ and $I L-22$ gene transcription were comparatively upregulated in 4-month-old $M u c 2^{-/-}$mice (Figure $4 \mathbf{d}$ and e). Thus, while modest differences were noted in the immune/inflammatory response between the two mouse strains, the exaggerated epithelial pathology seen in the $M u c 2^{-/-}$mice appears to likely depend on other factors.

\section{RELM- $\beta$ induces antimicrobial lectin expression in the colons of $\mathrm{Muc2}^{-/-}$mice}

To determine whether the exaggerated colitis in the $M u c 2^{-1-}$ mice could instead reflect abnormal host-microbe interactions, we analyzed gene transcript levels for several antimicrobial factors, including the lectins RegIII $\beta$ and RegIII $\gamma$, defensins ( $\beta$-defensin 1 and $\beta$-defensin 3 ) and inducible nitric oxide synthase (iNOS). Although only minor differences in defensins and $i N O S$ transcript levels were noted between $M u c 2^{-/-}$and $M u c 2^{-/-} /$Retnlb $^{-/-}$mice, 2-month-old $M u c 2^{-/-}$mice showed a 1,600- and 340-fold increase in RegIII $\beta$ and RegIII $\gamma$ gene transcripts as compared with $M u c 2^{-/-} /$Retnlb $^{-/-}$mice (Figure 5a). Interestingly, while RegIII $\beta$ and RegIII $\gamma$ gene transcripts ultimately did show a modest increase in $\mathrm{Muc2^{-/- }}$ Retnlb $^{-1-}$ mice at 4 months of age, these genes were still transcribed at 36- and sixfold higher levels in age-matched $M u c 2^{-/-}$mice (Figure 5b). Based on the dramatic elevation of the RegIII $\beta$ gene and the tools available to study this lectin, ${ }^{23}$ we focused our subsequent analysis on its expression and function.

Corresponding with RegIII $\beta$ 's dramatically upregulated transcription, intense and widespread RegIII $\beta$ immunostaining localized to the colonic epithelium was found in 2-month-old $M u c 2^{-/-}$mice, but not in $M u c 2^{-/-} /$Retnlb $^{-/-}$mice. By 4 months, modest RegIII $\beta$ staining was also observed in the $M u c 2^{-/-} /$Retnlb $^{-/-}$mice. Although RegIII $\beta$ staining in 4-month $\mathrm{Muc}^{-/-}$mice was reduced compared with levels at 2 months, it was still dramatically stronger than that seen in $M u c 2^{-/-} /$Retnlb $^{-/-}$mice (Figure 5c). Additional western blotting of colonic crypts and whole tissue lysates demonstrated thick RegIII $\beta$ bands from $M u c 2^{-/-}$mouse tissues at both 2 and 4 months of age, whereas the RegIII $\beta$ signal was minimal from $\mathrm{Muc2}^{-/-} /$Retnlb $^{-/-}$mouse tissues (Supplementary Figure S2A). To determine whether RegIII $\beta$ was secreted into the colonic lumen, stool samples from $M u c 2^{-/-}$mice were probed for RegIII $\beta$ by western blotting. RegIII $\beta$ was readily detected in the stool of $M u c 2^{-/-}$mice (Figure 5d), but not $M u c 2^{-/-}$/ Retnlb $^{-/-}$mice. Additional western blotting on these same $M u c 2^{-/-}$stool lysates confirmed distinct bands of RELM- $\beta$, whereas it was absent from Retnlb $^{-/-}$and $M u c 2^{-/-} /$Retnlb $^{-/-}$stool (Supplementary Figure S2B). To clarify the cellular source of the RegIII $\beta$, co-staining of colon sections revealed substantial RegIII $\beta$ staining in cells that were also positive for the epithelial cell marker E-cadherin, confirming epithelial cells as the major source of RegIII $\beta$ (Figure 5e). To determine whether RELM- $\beta$ could directly induce RegIII $\beta$ and RegIII $\gamma$ lectins, mouse epithelial CMT-93 cells were treated with recombinant RELM- $\beta$. At $4 \mathrm{~h}$ post treatment, a significant 2.7- and sixfold increase in RegIII $\beta$ and RegIII $\gamma$ transcription (respectively) was observed in RELM$\beta$-treated cells as compared with untreated cells (Figure 5f). Overall, these results demonstrate that RELM- $\beta$ exerts significant control over epithelial expression of the antimicrobial lectin RegIII $\beta$ in the colons of $M u c 2^{-/-}$mice.

\section{Commensal microbial dysbiosis in $\mathrm{Muc2}^{-/-}$mice is exaggerated in the presence of RELM- $\beta$}

Notably, $M u c 2^{-/-}$mice were recently shown to carry an aberrant gut microbiome that potentially promotes their colitis. ${ }^{24}$ Considering their significant secretion of the antimicrobial lectin $\operatorname{RegIII} \beta$, we assessed whether it impacted their microbiota. We first analyzed colon tissues for bacterial localization using a eubacterial (EUB) fluorescent in situ hybridization (FISH) probe that detects all bacteria. Significant numbers of adherent bacteria were noted on the colonic mucosal surface of both $M u c 2^{-/-}$and $M u c 2^{-1-} /$ Retnlb $^{-1-}$ mice, along with staining in the colonic submucosa suggesting bacterial translocation (Figure 6a). Quantitation of total commensal microbes in the stool by 4',6'-diamidino-2phenylindole staining revealed no significant differences between the two mouse strains (Figure 6b). Using primers specific for $16 \mathrm{~S}$ ribsosomal RNA, we confirmed that $M u c 2^{-/-}$ mice possess an aberrant microbiota as compared to C57BL/6 mice, including reduced levels of Lactobacilli (Supplementary Figure S3A). However, when we compared the colon contents

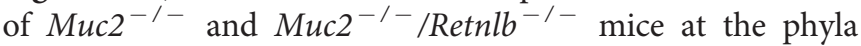
level, Bacteriodetes, and Firmicutes levels were similar, although there was a trend towards more $\gamma$-Proteobacteria in the $M u c 2^{-/-}$mice. In contrast, when the colon contents were analyzed at the species level (Segmented Filamentous Bacteria, Lactobacillus spp. and Clostridia spp.), the Muc2 $2^{-/-} /$Retnlb $^{-/-}$ mice were found to carry significantly more Gram + ve Lactobacilli bacteria ( 8.5 and 3 fold) than the $M u c 2^{-/-}$mice at 2 and 4 months respectively (Figure $\mathbf{6 c}$ and $\mathbf{d}$ ). The retention of Lactobacilli in the colons of $M u c 2^{-/-} /$Retnlb $^{-/-}$mice was confirmed by FISH staining, using probes designed to detect several Lactobacilli spp. (Supplementary Figure S3B).

Considering the dysbiotic microbiota seen in the $M u c 2^{-/-}$ mice, we asked whether it was exposure to these microbes that drove the upregulated RELM- $\beta$ expression. To test this, 12week old $M u c 2^{-/-}$mice were given peroral treatment of $200 \mu \mathrm{l}$ of an antibiotic mixture for 8 days. A significant reduction in RELM- $\beta$ immunoreactive goblet cells was noted in colonic sections of antibiotic treated mice in comparison to untreated mice confirming a key role for the microbiota in driving RELM$\beta$ expression (Supplementary Figure S3C).

\section{RELM- $\beta$ induced RegII/ $\beta$ mediates the antimicrobial effect on Lactobacilli spp.}

While our data indicated that $M u c 2^{-/-}$mice carried significantly fewer Lactobacilli than $M u c 2^{-/-} /$Retnlb $^{-/-}$ mice, the basis for this microbial dysbiosis was unclear. Using two Lactobacilli isolates from wildtype mice showing close resemblance to $L$. gasseri and $L$. johnsonii sub-species respectively, we tested whether RELM- $\beta$ exerted any direct antimicrobial activity but found no effect (not shown). We next 
a

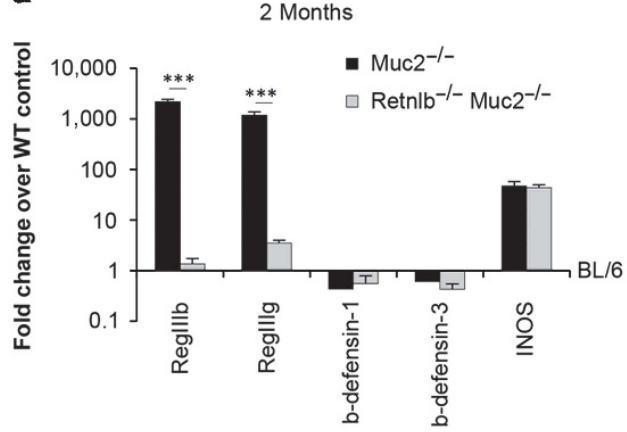

C
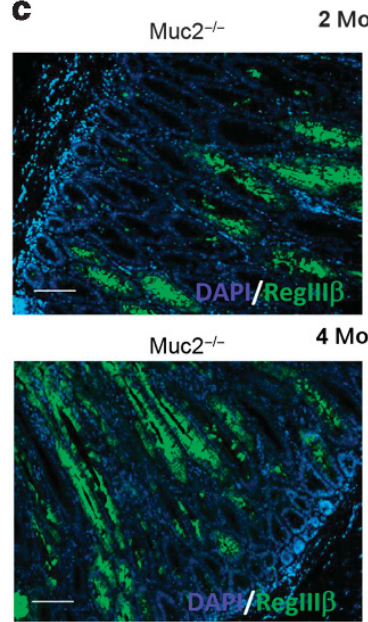

4 Months

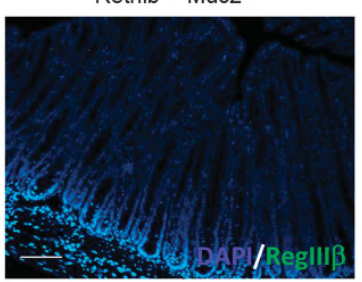

Retnlb $^{-/-}$Muc2-/- $^{-1}$

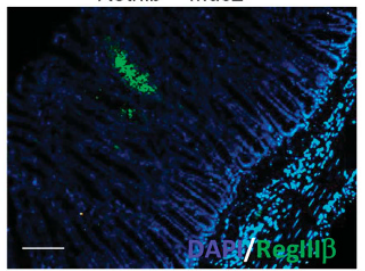

e

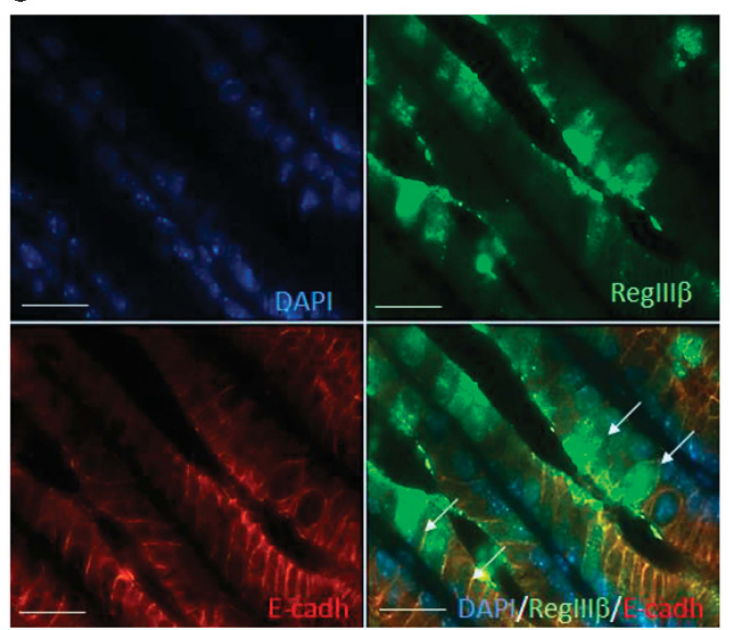

b

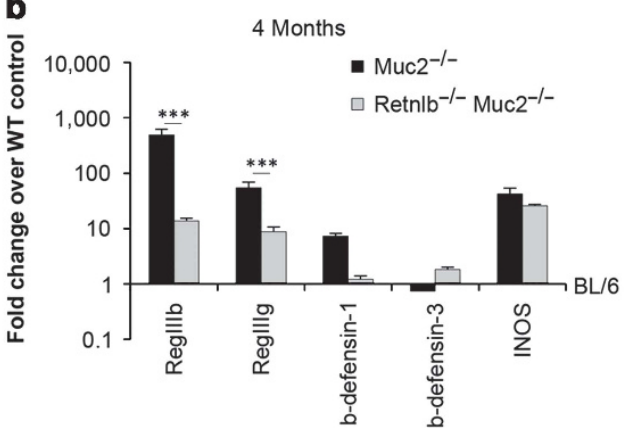

d

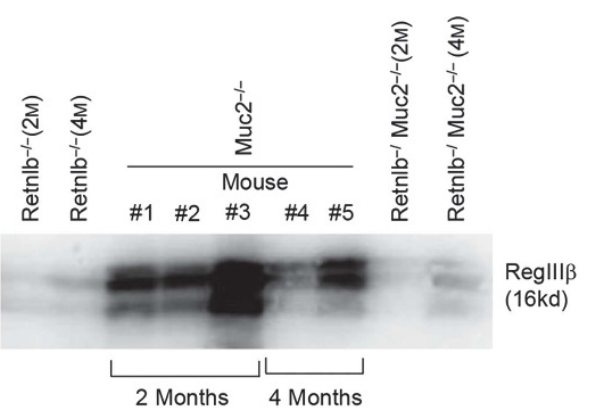

f

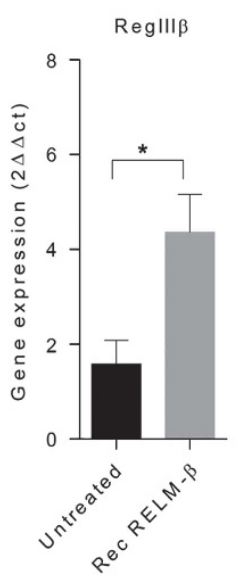

Figure 5 RELM- $\beta$ induced upregulated transcription of antimicrobial lectin genes in Muc2 $^{-/}$mice. Antimicrobial gene transcription analysis identified

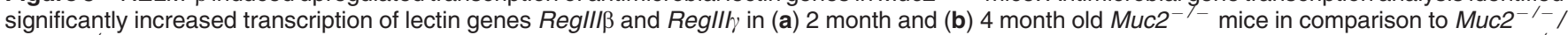
Retnlb ${ }^{-1-}$ mice. (c) Sections of colons stained for Regll/ $\beta$ also revealed strong staining on the colonic mucosal surface of 2- and 4-month-old Muc2 ${ }^{-/-}$ mice. (d) Stool samples probed to detect Regll/ $\beta$ also exhibited thick western blot bands in the samples from Muc2 ${ }^{-/-}$mice suggesting the protein is secreted into the intestinal lumen. (e) Colon sections of 4 months old $M u c 2^{-/-}$mice co-immunostained with RegII/ $\beta$ and E-cadherin reveal epithelial production of Reg/l/ $\beta$. (f) RT-PCR analysis on CDNA obtained from CMT-93 cells demonstrates upregulated transcription of RegII/ $\beta$ and Reglll/ genes in cells incubated with recombinant RELM- $\beta\left(100 \mathrm{ng} \mathrm{ml}^{-1}\right)$. For $\mathbf{a}$ and $\mathbf{b} n=4$ mice per group, for $\mathbf{d} n=2-3$ per group, and $\mathbf{e}$ and $\mathbf{f} n=3$ per group, repeated twice. Original magnification $\times 200$ for $\mathbf{c}$ and $\times 650$ for e; representative results were shown for gene transcription and Student's $t$-test and MANOVA was used to get statistical significance. cDNA, complementary DNA; MANOVA, multivariate analysis of variance; Muc, mucin; RELM- $\beta$, resistin-like molecule-beta; RT-PCR, reverse transcriptase-PCR.

examined the lectin RegIII $\beta$, testing the effects of recombinant RegIII $\beta$ as well as crypt supernatants obtained from 2 and 4 month old $M u c 2^{-/-}$and $M u c 2^{-/-} /$Retnlb $^{-/-}$mice.
Western blotting confirmed high levels of the RegIII $\beta$ lectin only in the supernatants of the $M u c 2^{-/-}$mice (Figure 7a). Upon incubating the mouse Lactobacilli isolates with the crypt 
a

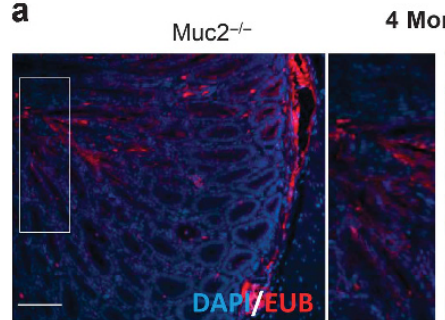

4 Months

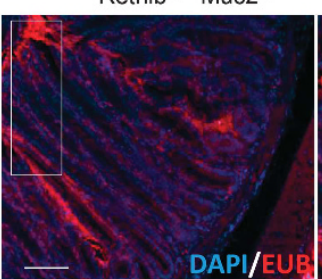

b

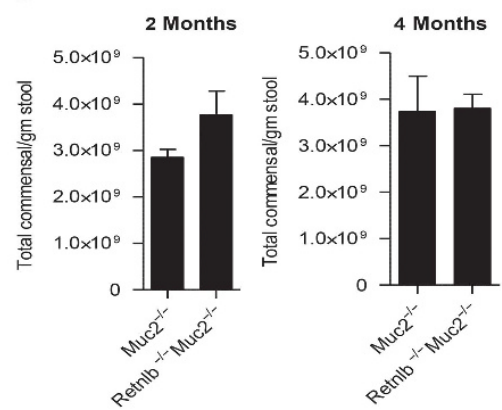

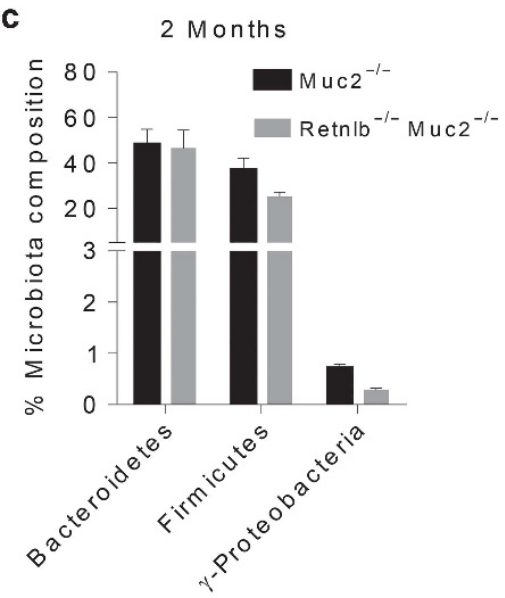
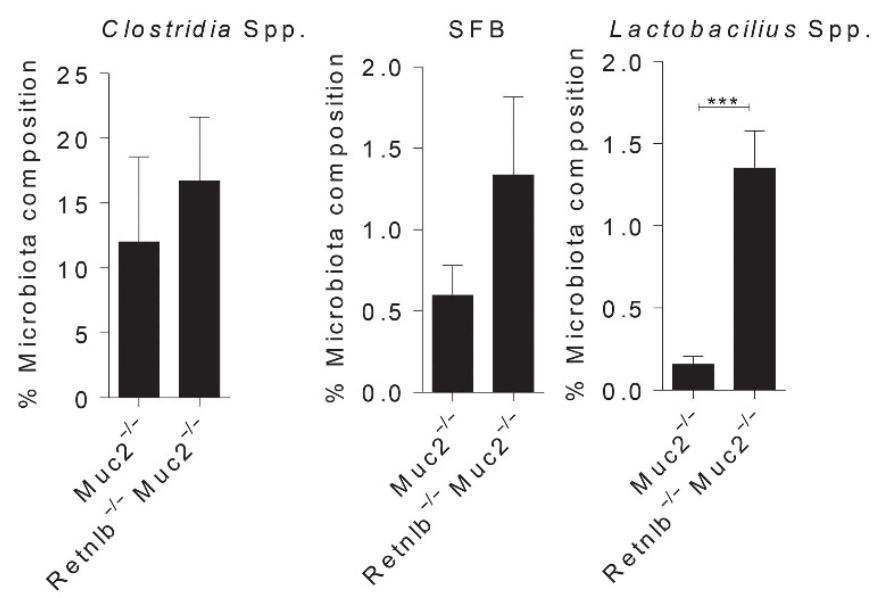

d
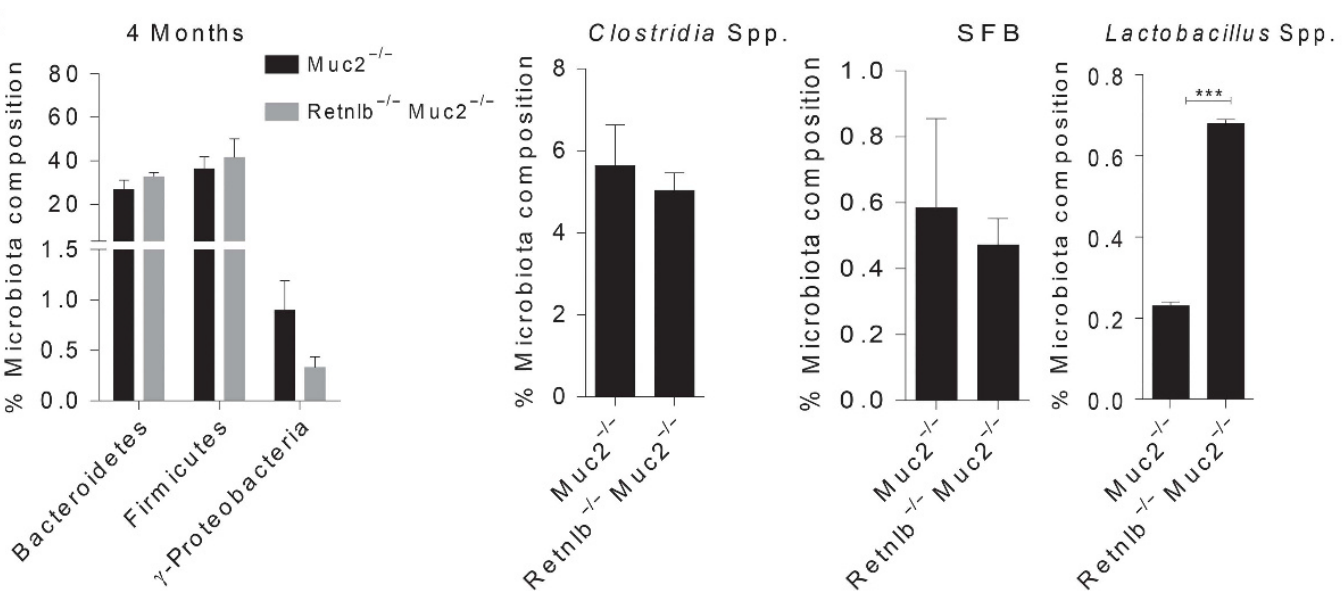

Figure 6 Altered commensal microbe populations in $\mathrm{Muc2}^{-/-}$and $M u c 2^{-/-} /$Retnlb ${ }^{-/-}$mice. (a) FISH hybridization using a probe recognizing all

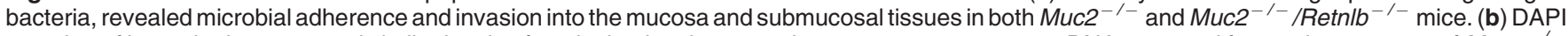
counting of bacteria demonstrated similar levels of total microbes between the two mouse genotypes. DNA extracted from colon contents of $M$ Mc2 $^{-1}$ and $\mathrm{MuC2}^{-1-} /$ Retnlb $^{-/-}$mice showed significant changes in the makeup of the microbiota at the species level in (c) 2-month and (d) 4-month-old mice. Results were shown as an average of three independent experiments with $n=3-4$ per group. $T$-tests were used to calculate the significance between each taxonomic group from stool samples of $\mathrm{Muc2}^{-/-}$and $\mathrm{Muc2}^{-/-} /$Retnlb $^{-/-}$mice ${ }^{\star \star \star} P<0.0001$. DAPI, 4',6'-diamidino-2-phenylindole;

FISH, fluorescent in situ hybridization; Muc, mucin.

supernatants, the $\mathrm{Muc2}^{-/-} /$Retnlb $^{-/-}$supernatants at 2 months promoted bacterial growth, while at 4 months, they showed only minimal antimicrobial activity against Lactobacilli (Figure $7 \mathbf{b}$ and $\mathbf{c})$. In contrast, significant bactericidal effect was observed with supernatants obtained from $\mathrm{Muc}^{-1-}$ mice (at both 2 and 4 months), as well as with the recombinant RegIII $\beta$, confirming it is likely responsible for the ability of $\mathrm{Muc2}^{-/-}$mouse lysates to kill Lactobacilli.

\section{Targeted introduction of mouse Lactobacilli spp.} ameliorates colitis in $\mathrm{Muc2}^{-/-}$mice

Strains of Lactobacilli have previously proven beneficial in several models of colitis, so we hypothesized that their loss could contribute to the exaggerated colonic pathology seen in $M u c 2^{-1-}$ mice at 4 months of age. To clarify this, 3 month old $M u c 2^{-/-}$mice were given drinking water containing either our murine Lactobacilli isolates (1 and 2) or a commercial 
a
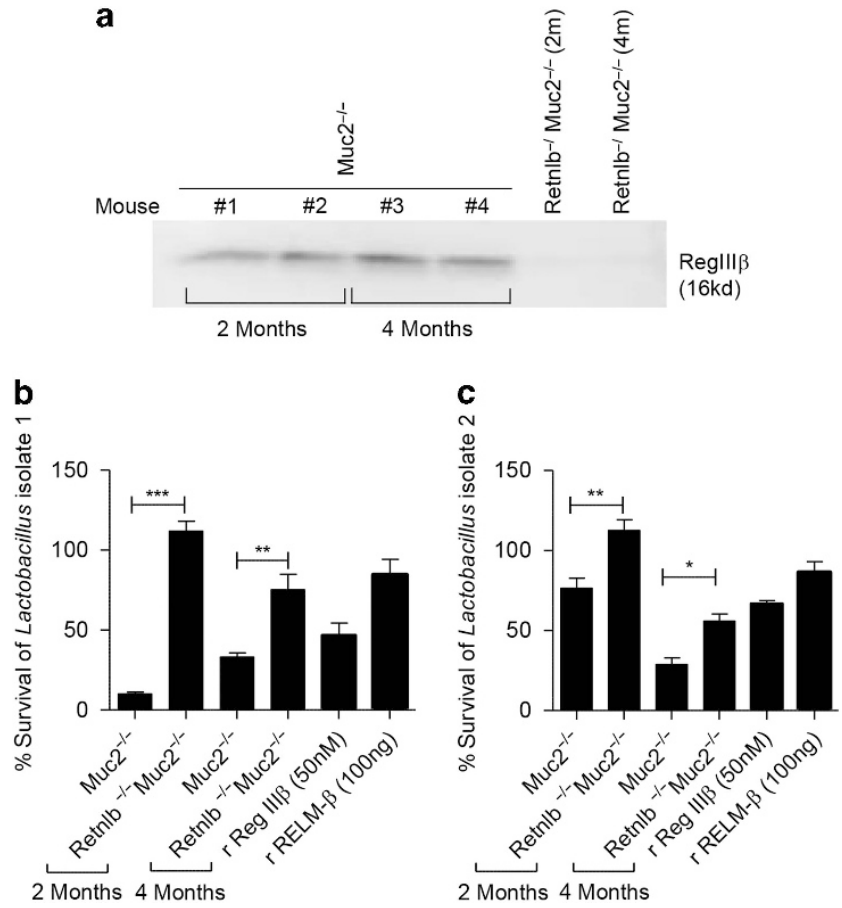

Figure 7 Antimicrobial effect of Reglll/ on the growth of mouse commensal Lactobacilli. (a) Western blot to detect Regll/ß identified the protein in the supernatants of crypts obtained from $\mathrm{Muc}^{-{ }^{-1}}$ but not $\mathrm{Muc2}^{-1-} /$ Retnlb $^{-1-}$ mice (2 and 4 months). These supernatants were also used for incubation with (b) Lactobacillus isolate 1 and (c) isolate 2. Muc2 $^{-1-}$ supernatants exhibited significant antimicrobial activity against these isolates, whereas little antimicrobial activity was seen with supernatants obtained from Muc2 ${ }^{-/-} /$Retn $^{\prime} b^{-/-}$mice. $N=2-3$ mice were used for each group and experiments were repeated three times. ANOVA ${ }^{*} P<0.05,{ }^{* *} P<0.001$ and ${ }^{* * *} P<0.0001$. ANOVA, analysis of variance; Muc, mucin.

source of human probiotics (VSL\#3) that contains a mixture of three Lactobacilli spp. The mice were then assessed for colitis at 4 months of age. Hematoxylin and eosin staining and colon pathology scoring of VSL\#3 treated mice noted a similarly severe colitis in the untreated and VSL\#3 treated mice (Figure 8a). In addition, VSL\#3 treated mice showed frequent RP and watery stools similar to untreated mice (Figure $\mathbf{8 b}$ and $\mathbf{c}$ ). In contrast, upon analyzing the $M u c 2^{-/-}$ mice treated with the murine Lactobacilli isolates, we noted a significant reduction in crypt abscesses and hyperplasia, submucosal edema, and mononuclear cell infiltration as well as improved maintenance of epithelial integrity, as compared to untreated $\mathrm{Muc2}^{-/-}$mice (Figure 8d). In addition, the Lactobacilli treated mice did not develop RP and none manifested diarrheic symptoms, whereas $15.3 \%$ of untreated mice exhibited RP and 55\% demonstrated loose stools (Figure 8e and $\mathbf{f}$ ). To confirm that administration of the Lactobacilli isolates altered the microbiome, $16 \mathrm{~s}$ ribsosomal RNA analysis of colon contents demonstrated a significant 3.5-fold increase in Lactobacilli levels in mice treated with Lactobacilli but not with VSL3 treatment (Figure 8g). Furthermore, FISH hybridization on stool samples also showed a fourfold increase in Lactobacilli numbers in the Lactobacilli-treated $\mathrm{Muc}^{-/-}$mice as compared with untreated mice (Supplementary Figure S4A). A dramatic reduction in RELM- $\beta$ and RegIII $\beta$ immunostaining was observed in Lactobacilli-treated mice but not in VSL3 or untreated mice suggesting that the Lactobacilli suppressed antimicrobial responses in the $\mathrm{Muc2}^{-/-}$mice (Supplementary Figure S4B). Interestingly, when $I L-17 A$ and $I L-22$ gene transcript levels were analyzed from colon tissues, a modest increase in IL-17A and a significant increase in IL-22 was observed in Lactobacilli-treated mice (Figure 8h). Taken together, these results indicate that targeted replacement of murine-derived Lactobacilli can ameliorate colitis in $\mathrm{Muc2}^{-/-}$mice.

\section{Upregulation of short-chain fatty acids in the colons of Lactobacilli treated Muc2 $^{-1-}$ mice}

To understand how Lactobacilli treatment suppressed colitis in $M u c 2^{-/-}$mice, we assayed the production of short-chain fatty acids (SCFA) in the colon contents of these mice. Specific bacterial species such as Lactobacilli are primary degraders of insoluble polysaccharides in the gut. This carbohydrate fermentation under anaerobic conditions produces SCFAs such as acetate, propionate, and butyrate, which protect against colitis and promote gut homeostasis. ${ }^{25}$ Our results demonstrated increased production of propionate and acetate in Lactobacillitreated mice when compared with untreated $\mathrm{Muc}^{-/-}$mice (Figure 9a). These results suggest that one mechanisms by which Lactobacilli spp. treatment attenuates colitis in $\mathrm{Muc}^{-{ }^{--}}$mice is by increasing the production of SCFA.

\section{DISCUSSION}

Intestinal goblet cells secrete several mediators including TFF3 and RELM- $\beta$, but they are best known for secreting the Muc2 that forms the protective intestinal mucus layer. ${ }^{26}$ In fact, several recent studies have highlighted the beneficial role this barrier has by limiting direct bacterial contact with the intestinal mucosa. Notably, mice impaired in the release of Muc2 are predisposed to developing colitis. The original goal of this study was to determine how intestinal goblet cells respond in the absence of Muc2, and whether they compensate by releasing other mediators in the context of colitis. Confirming previous studies, we found that after weaning, $\mathrm{Muc}^{-/-}$ mice develop colitis, in concert with a dramatic increase in the secretion of another goblet cell mediator, RELM- $\beta$. By generating mice lacking both Muc2 and RELM- $\beta$, we determined that compared with $\mathrm{Muc2}^{-/-}$mice, $\mathrm{Muc2}^{-/-}$/ Retnlb $^{-/-}$mice are delayed in their colitis development. Among its roles, RELM- $\beta$ upregulated RegIII $\beta$, an antimicrobial lectin that efficiently kills Gram-positive bacteria, causing a microbial dysbiosis that worsens the colitis in $\mathrm{Muc}^{-/-}$mice. Furthermore, we showed that targeted treatment with mouse commensal Lactobacilli in $\mathrm{Muc2^{-/- }}$ mice can dramatically reduce their colitis symptoms and pathology. In contrast, treatment with human probiotics was unable to resolve the colitis, highlighting the value of targeted bacterial therapeutic intervention.

Members of the resistin family were previously shown to promote insulin resistance and were linked to obesity, however, 
recent studies have highlighted their role as inflammatory mediators in the intestine. ${ }^{2,27,28}$ High levels of serum resistin were reported in IBD patients suggesting it as a possible marker for intestinal inflammation. ${ }^{29,30}$ Although RELM- $\beta$ expression was found highly induced in colonic goblet cells during several models of colitis, its role has remained unclear. We, and others, have reported the transcription of lectin genes increasing concurrently with the expression of RELM- $\beta$ during infectious or chemically induced colitis; ${ }^{22,31}$ however, its potential to regulate the makeup of the gut microbiome was untested. We
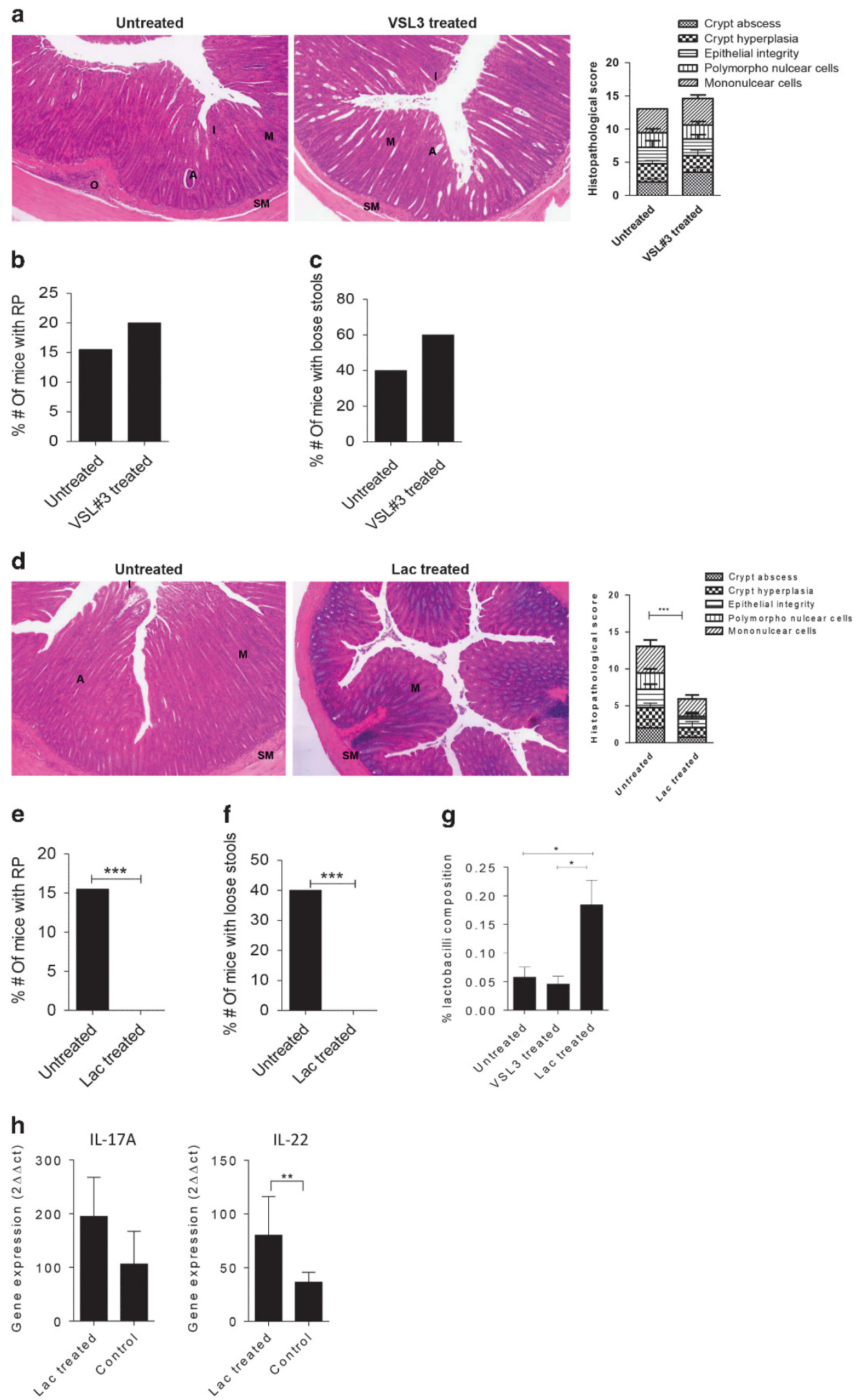
now show that RELM- $\beta$ promotes colitis by inducing changes in commensal bacteria through the induction of the antimicrobial lectin RegIII $\beta$. Of note, the modest induction of RegIII $\beta$ seen in $M u c 2^{-/-} /$Retnlb $^{-/-}$mice indicates that there are RELM- $\beta$-independent pathways regulating its expression, potentially reflecting the upregulated transcription of IL-22 observed in the $M u c 2^{-/-} /$Retnlb $^{-/-}$mice. IL-22 was previously demonstrated to modulate antimicrobial molecule expression during intestinal inflammation, ${ }^{32-34}$ including RegIII $\beta$ and RegIII $\gamma$ induction.

Antimicrobial lectins such as $\operatorname{RegIII} \alpha, \beta$, and $\gamma$ have been previously shown to protect gut homeostasis, potentially by spatially segregating the microbiota from the intestinal epithelium. ${ }^{35-37}$ Notably, we found RegIII $\beta$ was upregulated in $M u c 2^{-/-}$mice just after weaning, concurrent with a relative reduction in Lactobacilli, at least 1 month prior to overt colitis development. Thus, it takes time for the loss of Lactobacilli to promote the exaggerated pathology suffered by $M u c 2^{-/-}$ mice; however, the ability of oral administered Lactobacilli to ameliorate their colitis confirms their loss has a key role in the colitis development of $M u c 2^{-/-}$mice. It was intriguing that RELM- $\beta$ expression appeared to primarily affect Lactobacilli. This may reflect the susceptibility of these microbes to RegIII $\beta$ and other lectins, and/or their localization within the colonpotentially near the colonic epithelium. Notably, strains of Lactobacilli from humans have been well studied for their potential beneficial effects within the gastrointestinal tract. Treatment with Lactobacillus rhamnosus GG has been shown to be safe and potentially beneficial in maintaining remission in some UC patients. ${ }^{38}$ Similar treatment in combination with Lactobacillus acidophilus was used in a clinical study to treat UC (Ref: NCT00374725), while L. reuterii administration was found to protect against spontaneous enterocolitis in $I L-10^{-/-}$ mice. $^{39}$

Curiously, the effectiveness of Lactobacilli in large clinical trials has been mixed, potentially indicating only a subset of patients show benefit. This may suggest that probiotics only prove effective when they take up prolonged residence within the host intestine. Exactly how probiotic Lactobacilli confer protection to the host is still under study, but the ability of
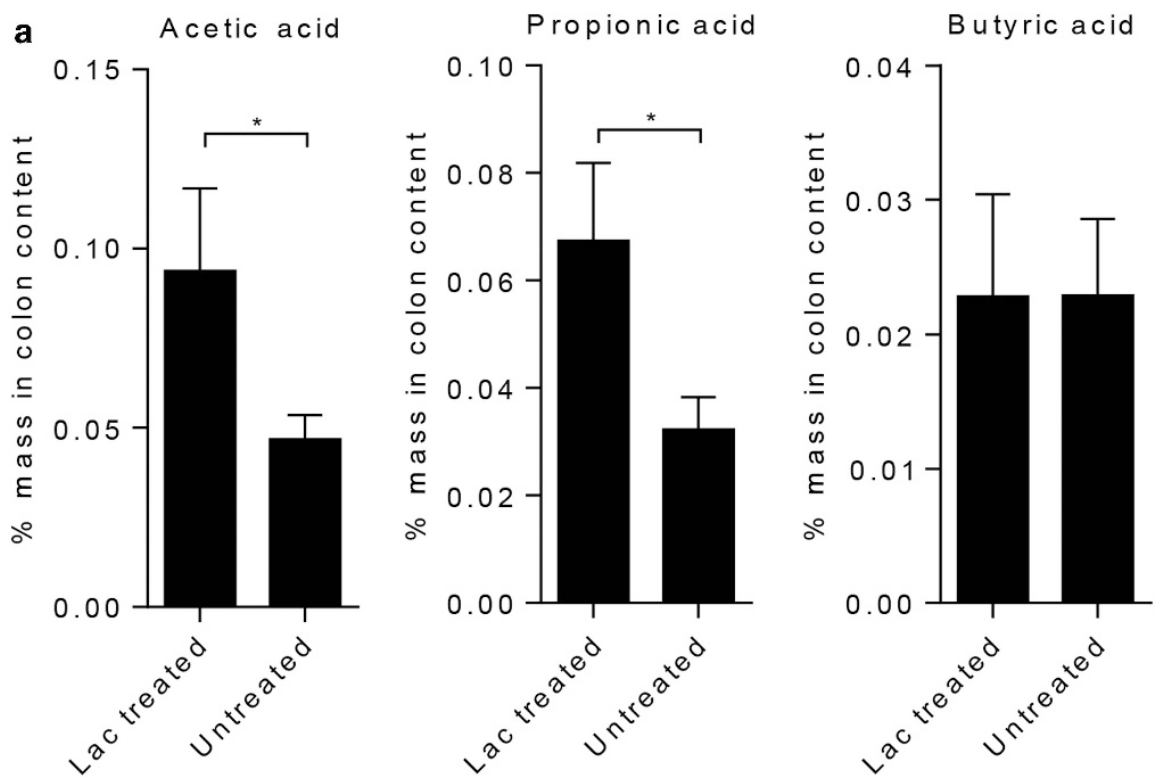

Figure 9 Increased short-chain fatty acid levels in Lactobacillus treated mice. (a) Colon contents analyzed for SCFA levels using gas chromatography demonstrated increased levels of acetic and propionic acid in Lactobacilli treated Muc2 ${ }^{-1-}$ mice in comparison with untreated Muc2 ${ }^{-1-}$ mice. Results shown represent an average of $n=6$ mice. Student's $t$-test ${ }^{*} P<0.05$. Muc, mucin; SCFA, short-chain fatty acid.

Figure 8 Murine Lactobacilli treatment reduces spontaneous colitis in 3- to 4-month-old Muc2 ${ }^{-/-}$mice. (a) Left panel: H\&E sections of colon tissues obtained from 4-month-old Muc2 ${ }^{-/-}$mice treated with the human probiotic mixture VSL\#3 in their drinking water for one month (started at age 3 months). Right panel: Histological scoring of H\&E stained colonic tissues showed no significant differences in histopathology between treated and untreated Muc2 $2^{-/-}$mice (b) similarly, no differences were observed in appearance of rectal prolapse and (c) stool consistency between the treated and untreated groups. However, (d) Muc2 ${ }^{-/-}$mice treated with a combination of mouse commensal Lactobacilli isolate 1 and 2 , showed overt protection from colitis as revealed by H\&E staining. In addition, no (e) rectal prolapses as well as (f) normally formed stools were observed in Lactobacilli treated mice. (g) Successful colonization was confirmed as colon contents of treated and untreated mice revealed increased colonization with commensal Lactobacilli isolate 1 and 2 in the Lactobacilli treated mice but not with human VSL3 treated mice. (h) RT-PCR analysis on cDNA obtained from Lactobacilli treated mice demonstrated a significant increase in the transcription of IL-22 in comparison to untreated mice $n=5$ per group repeated twice for ( $\mathbf{a}-\mathrm{g}$ ), $n=4$ for (h). Original magnification $\times 200$. Student's $t$-test and One-way ANOVA was used for $\mathbf{b}, \mathbf{c}, \mathbf{e}, \mathbf{f}$, and $\mathbf{g}$, respectively ${ }^{\star \star \star} P<0.0001$, ${ }^{\star \star} P<0.001,{ }^{\star} P<0.05$, A, crypt abscess; ANOVA, analysis of variance; cDNA, complementary DNA; H\&E, hematoxylin and eosin; I, inflammatory cell infiltration; IL-22, interleukin-22; Lu, intestinal lumen; M, mucosa; Muc, mucin; O, edema; RT-PCR, reverse transcriptase-PCR; SM, sub-mucosa. 
human-derived Lactobacilli to increase butyrate production by Clostridia species is one potential mechanism. ${ }^{40}$ In contrast, Lactobacilli strains derived from mice are less studied, and we found that their supplementation to $M u c 2^{-/-}$mice significantly increased acetate and propionate levels, but not butyrate. This increase in SCFA may be a key factor promoting mucosal healing in the Lactobacilli-treated $\mathrm{Muc}^{-/-}$mice. Notably, acetate and propionate have gained considerable attention due to their role in glucose metabolism and their ability to suppress $\mathrm{NF}-\kappa \mathrm{B}$, making them potentially useful in the treatment of IBD. ${ }^{41,42}$ Moreover, our results showing an increase in the gene transcript levels of IL-22 in Lactobacilli-treated group suggests a possible wound healing role of this cytokine during intestinal inflammation. ${ }^{43,44}$ Thus, the transcription of IL-22 along with the milieu of elevated protective SCFA, would have significantly contributed to limit colonic tissue damage and colitis observed in Lactobacilli-treated $M u c 2^{-/-}$mice. However, we do not exclude other possible reported mechanisms for the benefits of Lactobacilli treatment, such as competitive exclusion of pathogenic microbes, strengthening of tight junction proteins, and/or regulation of cytokine expression. ${ }^{45,46}$

In conclusion, these findings highlight a new role for intestinal goblet cells. Not only are they key protective cells that maintain the intestinal mucus barrier, but they can also act as potent drivers of intestinal inflammation, in this study, through the ability of RELM- $\beta$ to promote commensal microbial dysbiosis. Although Muc2 deficiency on its own altered the gut microbiome, it was the additional actions of RELM- $\beta$ that exaggerated the dysbiosis and worsened colitis in these mice. RELM- $\beta$ did this by directly upregulating RegIII $\beta$ expression that exerted its antimicrobial effects on Lactobacilli. Overall, these results not only provide insight into how altered goblet cell function can contribute to intestinal inflammation, but also demonstrate that specifically identifying depleted commensal bacterial species in UC patients and selectively reconstituting the same species could prove potentially therapeutic.

\section{METHODS}

Mice. Mucin 2 (Muc2) and Resistin like molecule beta (Retnlb) deficient mice (C57BL/6 background) were crossbred to generate $\mathrm{Muc2}^{-/-} /$Retnlb $^{-/-}$mice. Genotyping was performed using a DNA extraction kit (Qiagen, Toronto, Ontario, Canada) followed by amplification of wild-type and mutated $M u c 2$ and Retnlb alleles using PCR and agarose gels. Primer sequences were obtained from previous publications. ${ }^{12,47}$ All mice (including wild-type C57BL/6) were raised in-house, in sterilized, filter-topped cages, handled in biosafety cabinets, and fed autoclaved food and water under specific pathogenfree conditions. The protocols used were approved by the University of British Columbia's Animal Care Committee and in direct accordance with guidelines drafted by the Canadian Council on the Use of Laboratory Animals.

Tissue collection. Mice were anesthetized with isofluorane and killed via cervical dislocation. For microbiota analysis, fresh colon contents were collected and transferred into cryogenic vials. For histology, $0.5-\mathrm{cm}$ sections of distal colon were immediately placed in $10 \%$ neutral-buffered formalin (Thermo Fisher, Waltham, MA) and left at $4{ }^{\circ} \mathrm{C}$ overnight followed by transfer into $70 \%$ ethanol and paraffin embedding to cut $5-\mu \mathrm{m}$ sections. Distal colon sections $(0.5-1 \mathrm{~cm})$ were also collected and stored at $-80{ }^{\circ} \mathrm{C}$ in cryogenic vials or RNAlater (Qiagen) to run western blots and RNA extraction, respectively.

Cell culture. CMT-93 cells obtained from ATCC were cultured in Dulbecco's modified Eagle's medium supplemented with $10 \%$ fetal bovine serum, $20 \mathrm{mM}$ HEPES, $1 \%$ glutamine, penicillin $\left(100 \mathrm{U} \mathrm{ml}^{-1}\right)$ and streptomycin $\left(100 \mathrm{\mu g} \mathrm{ml}^{-1}\right.$; Sigma Chemicals Co., St. Louis, MD). Cells were maintained at $37^{\circ} \mathrm{C}$ in a humidified incubator with $5 \% \mathrm{CO}_{2}$ Cells grown to confluence were treated with recombinant RELM- $\beta$ protein $\left(100 \mathrm{ng} \mathrm{ml}^{-1}\right)$ for $4 \mathrm{~h}$ or left untreated as controls.

Immunostaining. Tissue sections were deparaffinized by heating at $56^{\circ} \mathrm{C}$ for $10 \mathrm{~min}$, cleared with xylene, and rehydrated through an ethanol gradient to water. A phosphate-buffered saline containing $2 \%$ goat or donkey serum, $1 \%$ bovine serum albumin, $0.1 \%$ Triton X-100, $0.05 \%$ Tween 20 , and $0.05 \%$ sodium azide was used to block the sections. Primary antibodies specific for Muc2 (Santa Cruz Biotechnology, Dallas, TX), TFF3, RELM - $\beta$ (Peprotech, Rocky Hill, NJ), Ly6g (BD Biosciences, Mississauga, Ontario, Canada), F4/80 (AbD Serotec, Raleigh, NC), CD3 (Abcam, Toronto, Ontario, Canada), E-cadherin (BD Biosciences), and REGIII $\beta$ (R\&D, Minneapolis, MN) were all diluted in the same phosphate-buffered saline buffer (1:200) and incubated with tissue sections for $60 \mathrm{~min}$. Secondary antibodies included AlexaFluor 568-conjugated goat anti-rabbit immunoglobulin $\mathrm{G}$, and AlexaFluor 568-conjugated goat anti-mouse (all obtained from Invitrogen (Burlington, Ontario, Canada) and used at 1:2000). Tissues were mounted using ProLong Gold Antifade reagent (Invitrogen) containing 4',6'-diamidino-2-phenylindole for DNA staining. Sections were viewed using a Zeiss AxioImager microscope equipped with an AxioCam HRm camera (Munich, Germany).

\section{Quantitative PCR analysis of cells, tissues, and stool samples.} Total RNA from CMT-93 cells and colon tissues was extracted using the Qiagen RNeasy kit, as per manufacturer's recommendations and $2 \mu \mathrm{g}$ of RNA was used to generate complementary DNA using the Qiagen Omniscript RT kit. Colon contents were pre-weighed and DNA was extracted using the Stool DNA Mini Kit (Qiagen) according to their protocol. DNA was quantified using a NanoDrop Spectrophotometer (ND1000) and quantitative PCR was performed by adding $5 \mu \mathrm{l}$ of either complementary DNA or stool DNA to $15 \mu \mathrm{l}$ PCR reaction mix containing $10 \mu \mathrm{l}$ SYBR green dye (Bio-Rad, Mississauga, Ontario, Canada) and $5 \mu \mathrm{l}$ comprised of RNase/DNase-free water and primers to a final concentration of $0.6 \mu \mathrm{M}$. All reactions were assembled in duplicate and quantitative PCR carried out using a Bio-Rad Opticon2. Melting point analysis confirmed the specificity of the PCR. Results were quantified using GeneEx Macro OM 3.0 software (Bio-Rad) following the $2 \Delta \Delta \mathrm{Ct}$ method. For commensal analysis, the relative abundance was determined by calculating average $\mathrm{Ct}$ value normalized to each primer's experimentally determined efficiency relative to the total 16S ribsosomal RNA bacteria (EUB). The specificity of Lactobacilli primers was further confirmed by ribsosomal RNA sequencing and blasting contig sequence in RDP program (East Lansing, MI). Primer sequences and reaction schemes are given in Table $\mathbf{1 .}$

Crypt isolation and antimicrobial assays. Longitudinally opened colon tissues $(0.5 \mathrm{~cm})$ were incubated for $2 \mathrm{~h}$ at $4{ }^{\circ} \mathrm{C}$ in Cell Recovery solution (Corning, NY) and gently agitated to dislodge crypts. Approximately 2,000 isolated crypts were resuspended in $40 \mu \mathrm{l}$ of iPIPES buffer (10 mm PIPES, $137 \mathrm{~mm} \mathrm{NaCl}, \mathrm{pH} 7.4)$ and incubated at $37^{\circ} \mathrm{C}$ for $30 \mathrm{~min}$ followed by centrifugation at 1,500 r.p.m. for $10 \mathrm{~min}$ to collect supernatants. Overnight bacterial cultures were serially diluted and aliquoted to 1,000 bacteria per $100 \mu \mathrm{l}$ per well into a 96 -well plate. After centrifugation at 1,500 r.p.m. for $10 \mathrm{~min}, 10 \mu \mathrm{l}$ of the appropriate crypt supernatant was added to the bacterial pellet and incubated for $2 \mathrm{~h}$. Bacterial pellets incubated with only recombinant RegIII $\beta$ protein (R\&D), iPIPES buffer or water, were used as controls. The bacteria were then plated and incubated overnight at $37^{\circ} \mathrm{C}$ and colony forming units counted. 
Table 1 Primer sets and PCR conditions

\begin{tabular}{|c|c|c|}
\hline Target mRNA & Primer sets & PCR cycle conditions ${ }^{a}$ denature/anneal/extend \\
\hline Muc3 & $\begin{array}{l}\text { Fwd: 5'-TGAGCAAAGGCAGTATCGTG-3' } \\
\text { Rev: 5'-GCCTCCTTCTTGCATGTCTC-3' }\end{array}$ & $94^{\circ} \mathrm{C}, 30 \mathrm{~s} / 55^{\circ} \mathrm{C}, 30 \mathrm{~s} / 72^{\circ} \mathrm{C}, 45 \mathrm{~s}$ \\
\hline Muc 6 & $\begin{array}{l}\text { Fwd: 5'-TGCATGCTCAATGGTATGGT-3' } \\
\text { Rev: 5'-TGTGGGCTCTGGAGAAGAGT-3' }\end{array}$ & $94^{\circ} \mathrm{C}, 30 \mathrm{~s} / 55^{\circ} \mathrm{C}, 30 \mathrm{~s} / 72^{\circ} \mathrm{C}, 45 \mathrm{~s}$ \\
\hline Muc 13 & $\begin{array}{l}\text { Fwd: 5'-TCTGGACTCTGGCCACTCTT-3' } \\
\text { Rev: 5'-GAGGACAGAGCCAGTCCAAG-3' }\end{array}$ & $94^{\circ} \mathrm{C}, 30 \mathrm{~s} / 55^{\circ} \mathrm{C}, 30 \mathrm{~s} / 72^{\circ} \mathrm{C}, 45 \mathrm{~s}$ \\
\hline IL-6 & $\begin{array}{l}\text { Fwd: 5'-GAGGATACCACTCCCAACAGACC-3' } \\
\text { Rev: 5'-AAGTGCATCATCGTTGTTCAT-3' }\end{array}$ & $94^{\circ} \mathrm{C}, 30 \mathrm{~s} / 59^{\circ} \mathrm{C}, 15 \mathrm{~s} / 72^{\circ} \mathrm{C}, 90 \mathrm{~s}+78^{\circ} \mathrm{C}, 5 \mathrm{~s}$ \\
\hline $\mathrm{IL}-17 \mathrm{a}$ & $\begin{array}{l}\text { Fwd: 5'-GCTCCAGAAGGCCCTCAGA-3' } \\
\text { Rev: 5'-CTTTCCCTC CGC ATTGACA-3'3 }\end{array}$ & $94^{\circ} \mathrm{C}, 30 \mathrm{~s} / 60^{\circ} \mathrm{C}, 30 \mathrm{~s} / 72^{\circ} \mathrm{C}, 30 \mathrm{~s}$ \\
\hline IL-17F & $\begin{array}{l}\text { Fwd: 5'-TGCTACTGTTGATGTTGGGAC-3' } \\
\text { Rev: 5'-AATGCCCTGGTITTGGTTGAA-3' }\end{array}$ & $94^{\circ} \mathrm{C}, 30 \mathrm{~s} / 55^{\circ} \mathrm{C}, 30 \mathrm{~s} / 72^{\circ} \mathrm{C}, 45 \mathrm{~s}$ \\
\hline IL-22 & $\begin{array}{l}\text { Fwd: 5'-ACCTTTCCTGACCAAACTCA-3', } \\
\text { Rev: 5'-AGCTTCTTCTCGCTCAGACG-3' }\end{array}$ & $94^{\circ} \mathrm{C}, 30 \mathrm{~s} / 58^{\circ} \mathrm{C}, 30 \mathrm{~s} / 72^{\circ} \mathrm{C}, 30 \mathrm{~s}$ \\
\hline IL-23p19 & $\begin{array}{l}\text { Fwd: 5'-TGGCTGTGCCTAGGAGTAGCA-3' } \\
\text { Rev:5'TTCATCCTCTTCTTCTCTTAGTAGATTCATA-3' }\end{array}$ & $94^{\circ} \mathrm{C}, 30 \mathrm{~s} / 60^{\circ} \mathrm{C}, 30 \mathrm{~s} / 72^{\circ} \mathrm{C}, 30 \mathrm{~s}$ \\
\hline IL-10 & $\begin{array}{l}\text { Fwd: 5'-GTTGCCAAGCCTTATCGGAA-3' } \\
\text { Rev: 5'-CCAGGGAATTCAAATGCTCCT-3' }\end{array}$ & $94^{\circ} \mathrm{C}, 30 \mathrm{~s} / 60^{\circ} \mathrm{C}, 30 \mathrm{~s} / 72^{\circ} \mathrm{C}, 45 \mathrm{~s}$ \\
\hline Reglll $\beta$ & $\begin{array}{l}\text { Fwd: 5'-CTGGTTTGATGCAGAACTGG-3' } \\
\text { Rev: 5'-TGACAAGCTGCCACAGAAAG-3' }\end{array}$ & $94^{\circ} \mathrm{C}, 30 \mathrm{~s} / 55^{\circ} \mathrm{C}, 30 \mathrm{~s} / 72^{\circ} \mathrm{C}, 45 \mathrm{~s}$ \\
\hline $18 \mathrm{~S}$ rRNA & $\begin{array}{l}\text { Fwd: 5'-GTAACCCGTTGAACCCCATT-3' } \\
\text { Rev: 5'-CCATCCAATCGGTAGTAGCG-3' }\end{array}$ & $94^{\circ} \mathrm{C}, 30 \mathrm{~s} / 55^{\circ} \mathrm{C}, 30 \mathrm{~s} / 72^{\circ} \mathrm{C}, 45 \mathrm{~s}$ \\
\hline GAPDH & $\begin{array}{l}\text { Fwd: 5'-AGAACATCATCCCTGCATCC-3' } \\
\text { Rev: 5'-CTGGGATGGAAATTGTGAGG-3' }\end{array}$ & $94^{\circ} \mathrm{C}, 30 \mathrm{~s} / 55-60^{\circ} \mathrm{C}, 30 \mathrm{~s} / 72^{\circ} \mathrm{C}, 30 \mathrm{~s}$ \\
\hline Bacteroides & $\begin{array}{l}\text { Fwd: 5'-GAGAGGAAGGTCCCCCAC-3' } \\
\text { Rev: 5'-CGCTACTTGGCTGGTTCAG-3' }\end{array}$ & $94^{\circ} \mathrm{C}, 30 \mathrm{~s} / 60^{\circ} \mathrm{C}, 30 \mathrm{~s} / 72^{\circ} \mathrm{C}, 45 \mathrm{~s}$ \\
\hline Firmicutes & $\begin{array}{l}\text { Fwd: 5'-GGAGYATGTGGTTAATTCGAAGCA-3' } \\
\text { Rev: 5'-AGCTGACGACAACCATGCAC-3' }\end{array}$ & $94^{\circ} \mathrm{C}, 30 \mathrm{~s} / 60^{\circ} \mathrm{C}, 30 \mathrm{~s} / 72^{\circ} \mathrm{C}, 45 \mathrm{~s}$ \\
\hline$\gamma$-Proteobacteria & $\begin{array}{l}\text { Fwd: 5'-TCGTCAGCTCGTGTYGTGA-3' } \\
\text { Rev: 5'-CGTAAGGGCCATGATG-3' }\end{array}$ & $94^{\circ} \mathrm{C}, 30 \mathrm{~s} / 60.5^{\circ} \mathrm{C}, 30 \mathrm{~s} / 72^{\circ} \mathrm{C}, 45 \mathrm{~s}$ \\
\hline SFB & $\begin{array}{l}\text { Fwd: 5'-CGGAGCATGTGGTTTAATTC-3' } \\
\text { Rev: 5'-GCTGTCTCGCTAAAGTGCTC-3' }\end{array}$ & $94^{\circ} \mathrm{C}, 30 \mathrm{~s} / 55^{\circ} \mathrm{C}, 30 \mathrm{~s} / 72^{\circ} \mathrm{C}, 45 \mathrm{~s}$ \\
\hline Lactobacilli & $\begin{array}{l}\text { Fwd: 5'-AGCAGTAGGGAATCTTCCA-3' } \\
\text { Rev: 5'-CACCGCTACACATGGAG-3' }\end{array}$ & $94^{\circ} \mathrm{C}, 30 \mathrm{~s} / 56^{\circ} \mathrm{C}, 30 \mathrm{~s} / 72^{\circ} \mathrm{C}, 45 \mathrm{~s}$ \\
\hline Clostridium & $\begin{array}{l}\text { Fwd: 5'-ATGCAAGTCGAGCGAKG-3' } \\
\text { Rev: 5'-TATGCGGTATTAATCTYCCTIT-3' }\end{array}$ & $94^{\circ} \mathrm{C}, 30 \mathrm{~s} / 55^{\circ} \mathrm{C}, 30 \mathrm{~s} / 72^{\circ} \mathrm{C}, 45 \mathrm{~s}$ \\
\hline EUB & $\begin{array}{l}\text { Fwd: 5'-TATGCGGTATTAATCTYCCTIT-3' } \\
\text { Rev: 5'-ATTACCGCGGCTGCTGGC-3' }\end{array}$ & $94^{\circ} \mathrm{C}, 30 \mathrm{~s} / 63^{\circ} \mathrm{C}, 30 \mathrm{~s} / 72^{\circ} \mathrm{C}, 45 \mathrm{~s}$ \\
\hline
\end{tabular}

Abbreviations: EUB, eubacteria; IFN- $\gamma$, interferon- $\gamma$; IL-22, interleukin-22; iNOS, inducible nitric oxide synthase; Muc, mucin; TNF $\alpha$, tumor necrosis factor- $\alpha$. ${ }^{a}$ All PCR experiments had an initial denaturing step of $95^{\circ} \mathrm{C}$ for $3-5$ min before commencement of PCR. 
Preparation of whole-tissue and crypt lysates. Crypts isolated as mentioned above were lysed on ice by pipetting up and down every $10 \mathrm{~min}$ for $30 \mathrm{~min}$ in RIPA buffer ( $150 \mathrm{~mm} \mathrm{NaCl}, 50 \mathrm{~mm}$ Tris $\mathrm{pH}$ 8.0, $0.1 \%$ SDS, $0.5 \%$ sodium deoxycholate, with $1 \%$ Triton X-100, $1 \%$ phosphatase inhibitor cocktail (Thermo Scientific, Burlington, Ontario, Canada) and protease inhibitor cocktail tablets (Roche, Mannheim, Germany)). Colon tissues (500 mg) were homogenized in $300 \mu \mathrm{l}$ of RIPA buffer using a MixerMill for $5 \mathrm{~min}$ at $30 \mathrm{~Hz}$ for $2 \mathrm{~h}$ at $4{ }^{\circ} \mathrm{C}$. Supernatants from tissue and crypt homogenates were collected following centrifugation at high speed (14,000 r.p.m. for $15 \mathrm{~min}$ at $\left.4{ }^{\circ} \mathrm{C}\right)$. The proteins in the supernatants were analyzed using the Dc Protein Assay kit (Bio-Rad).

Preparation of stool lysates. One to two stool pellets were harvested and placed in $500 \mu$ lof U9 buffer $(9 \mathrm{M}$ Urea, 2\%CHAPS, $50 \mathrm{~mm}$ Tris $\mathrm{pH}$ 9.0). Stool pellets were homogenized (as above) with a steel bead using a MixerMill and kept at room temperature for $1 \mathrm{~h}$ followed by mixing with $500 \mu \mathrm{l}$ of U1 buffer (0.9 м Urea, 2\% CHAPS, $50 \mathrm{~mm}$ Tris pH 9.0). Samples were then centrifuged at 14,000 r.p.m. for $10 \mathrm{~min}$, and the supernatant was collected and quantified using a Dc Protein Assay kit.

Western blot analysis of crypts, whole-tissue lysates, and stool samples. Lysates prepared from crypts, whole tissues and stool samples were resolved by SDS-PAGE and transferred onto $0.2 \mu \mathrm{m}$ polyvinylidene difluoride membranes (GE Healthcare, Buckinghamshire, UK). Membranes were blocked with $5 \%$ bovine serum albumin (Sigma, Oakville, Ontario, Canada) and probed using mouse anti-RELM- $\beta$, $\beta$-actin, or sheep anti-RegIII $\beta$ (all at 1:2,000 dilution). Blots were incubated with horseradish peroxidase-conjugated anti-mouse or anti-sheep secondary antibodies (1:10,000 dilutions) and exposed to the SuperSignal West Dura substrate (Thermo). Proteins bands were visualized using a ChemiDocXRS system (Bio-Rad).

FISH staining. Stool pellets were weighed, diluted in phosphatebuffered saline and fixed overnight in 37\% formalin. Samples were filtered through a $0.2 \mu \mathrm{m}$ Whatman membrane and rehydrated using ethanol. For FISH hybridization, deparaffinized colon sections and membrane filters were incubated overnight in the dark at $37^{\circ} \mathrm{C}$ with probes for either Lactobacilli AlexaFluor 488-conjugated $\left(5^{\prime}\right.$ GTCCATTGTGGAAGATTCCC-3') or total bacteria TexasRedconjugated EUB ( $5^{\prime}$-GCTGCCTCCCGTAGGAGT- $\left.3^{\prime}\right)$, diluted to a final concentration of $2.5 \mathrm{ng}^{-1}$ in hybridization buffer $(0.9 \mathrm{M} \mathrm{NaCl}$, $0.1 \mathrm{~m}$ Tris $\mathrm{pH} 7.2,30 \%$ Formamide, $0.1 \%$ SDS). After washing in dark for $15 \mathrm{~min}$ in a wash buffer $(0.9 \mathrm{M} \mathrm{NaCl}, 0.1 \mathrm{M}$ Tris $\mathrm{pH} 7.2,0.1 \%$ SDS $)$, samples were air dried and mounted on slides using 4',6'-diamidino-2phenylindole and visualized with a Zeiss AxioImager microscope (Göttingen, Germany). Stained bacteria were quantified as number of bacteria per gram of stool.

Histology and pathology scoring. Paraffin sections were deparaffinized and hematoxylin and eosin stained. Sections were mounted on microscope slides and visualized with a Zeiss AxioImager microscope. Histological scoring was based on previously adapted scoring systems. ${ }^{48,49}$

Probiotic and antibiotic treatment in $\mathrm{Muc2}^{-/-}$mice. 12-week-old $M u c 2^{-/}$mice were provided drinking water mixed with either $4 \times 10^{10}$ Lactobacillus isolates 1 and 2 (1:1) previously isolated from mice and sequenced to confirm the species identity, or water mixed with $1.25 \mathrm{gl}^{-1}$ of VSL\#3 probiotic blend (VSL\#3 Pharmaceuticals, North York, Ontario, Canada) containing a freeze dried blend of $B$. breve (DSM 24732), B. longum (DSM24736), B. infantis (SD5220DSM24737), L. acidophilus (DSM24735), L. plantarum (DSM24730), L. paracasei (DSM24733e), L. delbrueckii subsp Bulgaricus (DSM24733), and S. thermophiles (DSM24731) according to the manufacturer. Colon samples were harvested after 4 weeks of treatment and processed for analysis (as above). For antibiotic treatment, 12-week-old $M u c 2^{-/-}$mice were treated per-orally with
$200 \mu \mathrm{l}$ of antibiotics $\left(1 \mathrm{gl}^{-1}\right.$ ampicillin sodium, $0.51^{-1}$ vancomycin hydrochloride, $1 \mathrm{gl}^{-1}$ neomycin sulfate and $\mathrm{gl}^{-1}$ metronidazole) once a day for a period of 8 days and compared with untreated controls.

SCFA analysis. Using gas chromatography, the amount of acetic, propionic, and butyric acid was analyzed from colon samples as previously described. ${ }^{50}$ Briefly, colon samples were scraped into a fecal slurry and homogenized in isopropyl alcohol containing 2-ethylbutyric acid at $0.01 \% \mathrm{v} / \mathrm{v}$. The homogenate was centrifuged and the supernatant injected into a fused-silica FAMEWAX column (Restek Cat\#12498, Bellefonte, PA) on a trace 1,300 Gas Chromatograph equipped with flame-ionization detector and AI1310 autosampler (Thermo Scientific) in splitless mode. Peaks were analyzed on Chromeleon 7 Software (Sunnyvale, CA) and the areas under peaks for acetic, propionic, and butyric acid were represented as percent weight of total sample. Samples were normalized by measuring SCFAs in $50 \mathrm{mg}$ of colonic tissue content using $1 \mathrm{ml}$ of isopropyl alcohol solvent per sample.

Statistics. Results were expressed as means \pm s.e.m. of separate experiments. Graph Pad Prism 4 statistical software (GraphPad Software, San Diego, CA) was used to perform data analysis. Differences between means were calculated by Student's $t$-tests, $\chi^{2}$-test or analysis of variance (one-way, two-way or multiple) where appropriate. Specific differences were tested with Bonferroni's or post hoc Tukey test when comparing more than two groups. $P<0.05$ was considered statistically significant.

SUPPLEMENTARY MATERIAL is linked to the online version of the paper at http://www.nature.com/mi

\section{ACKNOWLEDGMENTS}

We would like to thank Dr Karen Madsen for providing the Lactobacilli isolates used in this study, Dr Sanjoy Ghosh for providing gas chromatography equipment to analyze SCFA and Dr Meera Nair for helpful discussions. Operating grants to B.A.V. from the Canadian Institutes for Health Research (CIHR) and Crohn's and Colitis Canada (CCC).

\section{AUTHOR CONTRIBUTIONS}

V.M., K.S.B, and B.A.V. conceived and designed the experiments. V.M., U.D., G.B., C.M., and T.H. performed the experiments.V.M. and U.D. analyzed the data: D.L.G. provided reagents, V.M., U.D., K.J., D.L.G., and B.A.V. wrote the paper.

\section{DISCLOSURE}

The authors declared no conflict of interest.

c) 2016 Society for Mucosal Immunology

\section{REFERENCES}

1. Sartor, R.B. Mechanisms of disease: pathogenesis of Crohn's disease and ulcerative colitis. Nat. Clin. Pract. Gastroenterol. Hepatol. 3, 390-407 (2006).

2. Matricon, J., Barnich, N. \& Ardid, D. Immunopathogenesis of inflammatory bowel disease. Self Nonself 1, 299-309 (2010).

3. Comito, D. \& Romano, C. Dysbiosis in the pathogenesis of pediatric inflammatory bowel diseases. Int. J. Inflamm. 2012, 687143 (2012).

4. Johansson, M.E., Larsson, J.M. \& Hansson, G.C. The two mucus layers of colon are organized by the MUC2 mucin, whereas the outer layer is a legislator of host-microbial interactions. Proc. Natl Acad. Sci. USA 108 (Suppl 1), 4659-4665 (2011).

5. Deplancke, B. \& Gaskins, H.R. Microbial modulation of innate defense: goblet cells and the intestinal mucus layer. Am. J. Clin. Nutr. 73, 1131S-1141S (2001).

6. Hansson, G.C. \& Johansson, M.E. The inner of the two Muc2 mucindependent mucus layers in colon is devoid of bacteria. Gut Microbes 1, 51-54 (2010). 
7. Fyderek, K. et al. Mucosal bacterial microflora and mucus layer thickness in adolescents with inflammatory bowel disease. World J. Gastroenterol. 15, 5287-5294 (2009).

8. Schwerbrock, N.M. et al. Interleukin 10-deficient mice exhibit defective colonic Muc2 synthesis before and after induction of colitis by commensal bacteria. Inflamm. Bowel Dis. 10, 811-823 (2004).

9. Johansson, M.E.V. et al. Bacteria penetrate the normally impenetrable inner colon mucus layer in both murine colitis models and patients with ulcerative colitis. Gut 63, 281-291 (2013).

10. Johansson, M.E. et al. Bacteria penetrate the inner mucus layer before inflammation in the dextran sulfate colitis model. PLOS ONE 5, e12238 (2010).

11. Van der Sluis, M. et al. Muc2-deficient mice spontaneously develop colitis, indicating that MUC2 is critical for colonic protection. Gastroenterology 131, 117-129 (2006).

12. Velcich, A. et al. Colorectal cancer in mice genetically deficient in the mucin Muc2. Science 295, 1726-1729 (2002).

13. Artis, D. et al. RELMbeta/FIZZ2 is a goblet cell-specific immune-effector molecule in the gastrointestinal tract. Proc. Natl Acad. Sci. USA 101, 13596-13600 (2004).

14. Herbert, D.R. et al. Intestinal epithelial cell secretion of RELM-beta protects against gastrointestinal worm infection. J. Exp. Med. 206, 2947-2957 (2009).

15. Steppan, C.M. et al. A family of tissue-specific resistin-like molecules. Proc. Natl Acad. Sci. USA 98, 502-506 (2001).

16. Krimi, R.B. et al. Resistin-like molecule beta regulates intestinal mucous secretion and curtails TNBS-induced colitis in mice. Inflamm. Bowel Dis. 14, 931-941 (2008).

17. He, W. et al. Bacterial colonization leads to the colonic secretion of RELMbeta/FIZZ2, a novel goblet cell-specific protein. Gastroenterology 125, 1388-1397 (2003).

18. Mishra, A. et al. Resistin-like molecule-beta is an allergen-induced cytokine with inflammatory and remodeling activity in the murine lung. Am. J. Physiol. Lung Cell. Mol. Physiol. 293, L305-L313 (2007).

19. Barnes, S.L. et al. Resistin-like molecule beta (RELMbeta/FIZZ2) is highly expressed in the ileum of SAMP1/YitFc mice and is associated with initiation of ileitis. J. Immunol. 179, 7012-7020 (2007).

20. Bergstrom, K.S. et al. Goblet cell derived RELM-beta recruits CD4 + Tcells during infectious colitis to promote protective intestinal epithelial cell proliferation. PLoS Pathog. 11, e1005108 (2015).

21. McVay, L.D. et al. Absence of bacterially induced RELMbeta reduces injury in the dextran sodium sulfate model of colitis. J. Clin. Invest. 116, 2914 2923 (2006).

22. Hogan, S.P. et al. Resistin-like molecule beta regulates innate colonic function: barrier integrity and inflammation susceptibility. J. Allergy Clin. Immunol. 118, 257-268 (2006).

23. Burger-van Paassen, N. et al. Mucin Muc2 deficiency and weaning influences the expression of the innate defense genes Reg3beta, Reg3gamma and angiogenin-4. PLOS ONE 7, e38798 (2012).

24. Huang, E.Y. et al. Using corticosteroids to reshape the gut microbiome: implications for inflammatory bowel diseases. Inflamm. Bowel Dis. 21, 963-972 (2015).

25. Vinolo, M.A., Rodrigues, H.G., Nachbar, R.T. \& Curi, R. Regulation of inflammation by short chain fatty acids. Nutrients 3, 858-876 (2011).

26. Specian, R.D. \& Oliver, M.G. Functional biology of intestinal goblet cells. Am. J. Physiol. 260 (2 Pt 1), C183-C193 (1991).

27. Banerjee, R.R. et al. Regulation of fasted blood glucose by resistin. Science 303, 1195-1198 (2004).

28. Nair, M.G., Guild, K.J. \& Artis, D. Novel effector molecules in type 2 inflammation: lessons drawn from helminth infection and allergy. J. Immunol. 177, 1393-1399 (2006).

29. Karmiris, K., Koutroubakis, I.E., Xidakis, C., Polychronaki, M., Voudouri, T. \& Kouroumalis, E.A. Circulating levels of leptin, adiponectin, resistin, and ghrelin in inflammatory bowel disease. Inflamm. Bowel Dis. 12, 100-105 (2006).

30. Konrad, A. et al. Resistin is an inflammatory marker of inflammatory bowel disease in humans. Eur. J. Gastroenterol. Hepatol. 19, 1070-1074 (2007).

31. Bhinder, G. et al. Intestinal epithelium-specific MyD88 signaling impacts host susceptibility to infectious colitis by promoting protective goblet cell and antimicrobial responses. Infect. Immun. 82, 3753-3763 (2014).

32. Wolk, K., Kunz, S., Witte, E., Friedrich, M., Asadullah, K. \& Sabat, R. IL-22 increases the innate immunity of tissues. Immunity 21, 241-254 (2004).

33. Rendon, J.L., Li, X., Akhtar, S. \& Choudhry, M.A. Interleukin-22 modulates gut epithelial and immune barrier functions following acute alcohol exposure and burn injury. Shock 39, 11-18 (2013).

34. Johansson, M.E., Thomsson, K.A. \& Hansson, G.C. Proteomic analyses of the two mucus layers of the colon barrier reveal that their main component, the Muc2 mucin, is strongly bound to the Fcgbp protein. J. Proteome Res. 8, 3549-3557 (2009).

35. Vaishnava, S. et al. The antibacterial lectin Reglllgamma promotes the spatial segregation of microbiota and host in the intestine. Science 334, 255-258 (2011).

36. Miki, T., Holst, O. \& Hardt, W.D. The bactericidal activity of the C-type lectin Reglllbeta against Gram-negative bacteria involves binding to lipid A. J. Biol. Chem. 287, 34844-34855 (2012).

37. Mukherjee, S. et al. Antibacterial membrane attack by a pore-forming intestinal C-type lectin. Nature 505, 103-107 (2014).

38. Zocco, M.A. et al. Efficacy of Lactobacillus GG in maintaining remission of ulcerative colitis. Aliment. Pharmacol. Ther. 23, 1567-1574 (2006).

39. Madsen, K.L., Doyle, J.S., Jewell, L.D., Tavernini, M.M. \& Fedorak, R.N. Lactobacillus species prevents colitis in interleukin 10 gene-deficient mice. Gastroenterology 116, 1107-1114 (1999).

40. Louis, P. \& Flint, H.J. Diversity, metabolism and microbial ecology of butyrate-producing bacteria from the human large intestine. FEMS Microbiol. Lett. 294, 1-8 (2009).

41. Tedelind, S., Westberg, F., Kjerrulf, M. \& Vidal, A. Anti-inflammatory properties of the short-chain fatty acids acetate and propionate: a study with relevance to inflammatory bowel disease. World J. Gastroenterol. 13, 2826-2832 (2007).

42. Anderson, J.W. \& Bridges, S.R. Short-chain fatty acid fermentation products of plant fiber affect glucose metabolism of isolated rat hepatocytes. Proc. Soc. Exp. Biol. Med. 177, 372-376 (1984).

43. Mizoguchi, A. Healing of intestinal inflammation by IL-22. Inflamm. Bowel Dis. 18, 1777-1784 (2012).

44. Pickert, G. et al. STAT3 links IL-22 signaling in intestinal epithelial cells to mucosal wound healing. J. Exp. Med. 206, 1465-1472 (2009).

45. Barshishat, M., Polak-Charcon, S. \& Schwartz, B. Butyrate regulates E-cadherin transcription, isoform expression and intracellular position in colon cancer cells. Br. J. Cancer 82, 195-203 (2000).

46. Casas, I.A. \& Dobrogosz, W.J. Validation of the probiotic concept: Lactobacillus reuteri confers broad-spectrum protection against disease in humans and animals. Microb. Ecol. Health Dis. 12, 247-285 (2000).

47. Hogan, S. et al. Resistin-like molecule beta regulates innate colonic function: barrier integrity and inflammation susceptibility. J. Allergy Clin. Immunol. 118, 257-268 (2006).

48. Bergstrom, K.S. et al. Muc2 protects against lethal infectious colitis by disassociating pathogenic and commensal bacteria from the colonic mucosa. PLoS Pathog. 6, e1000902 (2010).

49. Sham, H.P. et al. SIGIRR, a negative regulator of TLR/IL-1R signalling promotes Microbiota dependent resistance to colonization by enteric bacterial pathogens. PLoS Pathog. 9, e1003539 (2013).

50. Brown, K. et al. Prolonged antibiotic treatment induces a diabetogenic intestinal microbiome that accelerates diabetes in NOD mice. ISME J; advance online publication, 14 August 2015; doi:10.1038/ismej.2015.114 (2015). 